\title{
Digestion dans l'intestin grêle chez le Porc \\ 4. Cinétique de passage des digesta au niveau de la jonction iléo-caeco-colique et bilans de la digestion selon la nature de l'amidon et la source de protéines alimentaires
}

\author{
Béatrice DARCY, J.P. LAPLACE, P.A. VILLIERS \\ Avec la collaboration technique de Brigitte Mourot, Georgette Fredou, \\ A. Roger, A. Vergeylen \\ I.N.R.A., Laboratoire de Physiologie de la Nutrition \\ Centre national de Recherches zootechniques \\ 78350 Jouy-en-Josas (France)
}

\begin{abstract}
Résumé
Les influences respectives de la nature de lamidon et de la source de protéines alimentaires, ainsi que de l'interaction entre ces constituants de la ration, à l'égard de la digestion dans l'intestin grêle, font l'objet d'une étude selon un dispositif factoriel impliquant deux sources d'amidon purifié (de maìs ou de blé) et deux sources de protéines (farine de poisson ou gluten de blé) pour des régimes formulés à $16 \mathrm{p}$. 100 de matières azotées totales (tabl. 2). Parallèlement sont mis en cuuvre des régimes protéiprives à base de l'un ou l'autre des amidons purifiés. Cette étude prend en compte les aspects cinétiques, qualitatifs et quantitatifs du passage des digesta (matière fraîche, matière sèche, amidon, azote total et azote soluble) à l'extrémité distale de l'intestin grêle. Pour cela huit porcs mâles castrés de race Large White sont soumis à la fistulation iléo-colique post-valvulaire récemment développée au laboratoire, pour assurer la collecte totale des digesta, tels qu'ils sont réellement émis de l'intestin grêle vers le gros intestin au cours des 24 heures consécutives à l'ingestion d'un repas d'épreuve.
\end{abstract}

La cinétique de passage des principaux constituants des digesta est décrite. L'analyse de variance appliquée aux bilans de la digestion montre que : (i) la nature de l'amidon purifié influence significativement la digestibilité apparente de l'azote du régime qui est meilleure avec l'amidon de maïs qu'avec celui de blé ; (ii) la source de protéines alimentaires affecte de façon significative la digestibilité apparente de la matière sèche et celle de l'azote, qui sont plus élevées avec le gluten de blé qu'avec la farine de poisson; elle influence également de façon significative la digestibilité apparente de l'amidon, qui est meilleure avec la farine de poisson qu'avec le gluten de blé ; (iii) il existe une interaction significative entre amidon et protéine à l'égard de la digestibilité apparente de l'azote qui est la plus élevée pour l'association maïs-gluten. L'observation d'une meilleure digestibilité dans une situation donnée peut être rapprochée de particularités de la cinétique de passage.

\section{Introduction}

Une nouvelle technique, dite de fistulation iléo-colique post-valvulaire a été récemment proposée (DARCY, LAplace \& Villiers, 1980 a) pour collecter les digesta tels qu'ils sont normalement émis vers le gros intestin. La préservation du rôle fonctionnel du sphincter iléo-caeco-colique, autorisée par cette technique, conduit 
à des estimations différentes du transit des digesta à l'extrémité distale de l'intestin grêle par rapport aux techniques classiques (DARCY \& LAPLACE, 1980). Le séjour des digesta dans l'intestin grêle s'avère plus long de 60 à $90 \mathrm{mn}$, ce qui conduit à l'émission vers le gros intestin de quantités plus faibles de matériaux à teneur en matière sèche plus élevée.

Cette amélioration des conditions d'obtention des digesta a également des conséquences importantes pour l'évaluation de la digestibilité partielle des aliments à l'extrémité distale de l'intestin grêle (Darcy, Laplace \& Villiers, 1980 b). En effet, la digestibilité de l'azote des régimes pauvres en protéines $(8$ p. 100) n'est pas médiocre, contrairement à ce qui est observé lors de dérivation iléale. L'influence de la nature de l'amidon sur la digestion des protéines n'est mise en évidence que Iors de dérivation post-valvulaire. Indépendamment de ces aspects méthodologiques, il est apparu que la digestibilité apparente de l'amidon de blé est légèrement supérieure à celle de l'amidon de maïs $(99,8$ vs. 99,4 p. 100) et que l'abaissement du taux protéique de la ration entraîne une réduction de la digestibilité de l'amidon (de l'ordre de 5 p. 100 dans le cas d'un régime protéiprive).

L'objet du présent travail est d'évaluer l'influence respective de la nature de l'amidon et de la source de protéines alimentaires ainsi que les interactions entre ces deux facteurs, sur la digestion dans l'intestin grêle. Cette étude est fondée sur la mise en œuvre exclusive de la fistulation iléo-colique post-valvulaire qui seule permet la collecte des digesta tels qu'ils sont normalement émis vers le gros intestin. Elle s'insère dans un ensemble de travaux visant à préciser parallèlement, pour les mêmes régimes, l'évacuation gastrique (LAPLACE et al., 1981) ainsi que la digestibilité des acides aminés à la fin de l'intestin grêle (DARCY, 1980) et la digestibilité globale mesurée au niveau des fèces (DARCY \& LAPLACE, 1981).

\section{Matériel et méthodes}

\section{1. - Schéma expérimental et animaux}

L'expérience a été réalisée selon un schéma factoriel $2 \times 2$, fondé sur les combinaisons de deux amidons purifiés (maïs et blé) et de deux sources de protéines (farine de poisson et gluten de blé). Au total, 8 porcs mâles castrés de race Large White ont été utilisés, à raison de 2 par régime. Toutefois, pour des raisons matérielles (nombre de cages) mais aussi pratiques (temps nécessaire pour les collectes et surveillance des animaux), l'expérience a été conduite en deux temps : étude des régimes à base d'amidon de maïs, puis étude des régimes à base d'amidon de blé.

L'affectation des animaux aux différents régimes, réalisée au hasard, ainsi que le poids vif et la durée d'utilisation des 8 porcs sont précisés dans le tableau 1. Tous ces porcs ont subi la fistulation iléo-colique post-valvulaire selon la technique décrite par Darcy, Laplace \& Villiers (1980 a). Toutefois, la durée de vie expérimentale limitée des porcs $G$ et $H$ résulte dans les deux cas de l'éviction progressive de la canule de verre avec arrachage. Aussi, pour les porcs du régime blé, une étape chirurgicale supplémentaire a-t-elle été ajoutée, consistant en un doublage de la poche de tissu caeco-colique par un tissu de polyester médical (Rhodergon ${ }^{\circledR}$ ). Cette préparation s'est avérée très efficace en évitant la distension de la poche caeco-colique et 
l'éviction des canules de verre. La durée de vie expérimentale réduite du porc J ainsi préparé résulte d'un bris accidentel de canule contre les parois de la cage. A noter enfin que le porc $\mathrm{K}$, initialement utilisé pour un régime gluten de blé a ensuite reçu un régime farine de poisson pour compenser le nombre limité d'épreuves réalisées avec l'aliment gluten de blé chez le porc $\mathbf{J}$ accidenté.

Dans tous les cas, l'autopsie a montré un aspect normal de la saillie valvulaire dans la poche de tissu caeco-colique et l'absence d'hypertrophie de travail de l'iléon dans lequel aucune accumulation anormale de digesta n'a été constatée.

\section{2. - Alimentation des animaux}

Les aliments définis par les combinaisons du schéma factoriel sont désignés par commodité de la façon suivante : maïs-poisson, maïs-gluten, blé-poisson, blé-gluten. Ces quatre aliments sont formulés de façon à assurer un taux de matières azotées de 16 p. 100. Leurs compositions sont indiquées dans le tableau 2. Parallèlement, deux aliments protéiprives, obtenus par substitution d'amidon de maïs ou de blé à la source protéique, ont été utilisés (tabl. 2).

Les porcs sont habitués dès la réalimentation post-opératoire à ingérer l'un ou l'autre des régimes à 16 p. 100 de matières azotées. Cette réalimentation est conduite progressivement, au terme d'un jeûne post-opératoire de 36 heures, selon un plan de rationnement amenant l'animal de 2 repas quotidiens de $200 \mathrm{~g}$ de farine fraîche chacun, à un repas unique de 1000 à $1200 \mathrm{~g}$. La distribution d'un seul repas quotidien, en dépit de la restriction qu'elle implique, est adoptée de préférence à l'emploi de marqueurs, pour permettre l'étude de la cinétique de passage des matériaux alimentaires. Les repas d'épreuve sont distribués systématiquement le matin à 9 h 00 , la quantité de farine fraîche étant diluée par 2 fois son poids d'eau. Dans quelques cas, l'aliment protéiprive est distribué, à la même heure et sous íes mêmes conditions de dilution, mais sans accoutumance préalable.

\section{3. - Collecte et restitution des digesta}

Les digesta émis au niveau de la valvule iléo-caeco-colique sont recueillis dans un ballon de caoutchouc monté sur la canule de dérivation (DARCY, LAPLACE \& VILLIERS, 1980 a). Dans l'intervalle des expérimentations, le ballon est vidé trois fois par 24 heures. Il est enlevé quotidiennement pour permettre son nettoyage et le contrôle de la perméabilité de la canule.

$\mathrm{Au}$ cours des nycthémères expérimentaux, les digesta sont recueillis $4,6,8,10$, 14 et 24 heures après l'ingestion à 9 h $00 \mathrm{du}$ repas d'épreuve. Après échantillonnage, les digesta collectés sont stockés à $+4{ }^{\circ} \mathrm{C}$. Après réchauffement, ils sont restitués à l'animal, par la canule colique, en une seule fois chaque jour. Cette réintroduction est assurée par gravité, en 5 à $10 \mathrm{mn}$ selon la quantité, après l'ingestion du repas. 


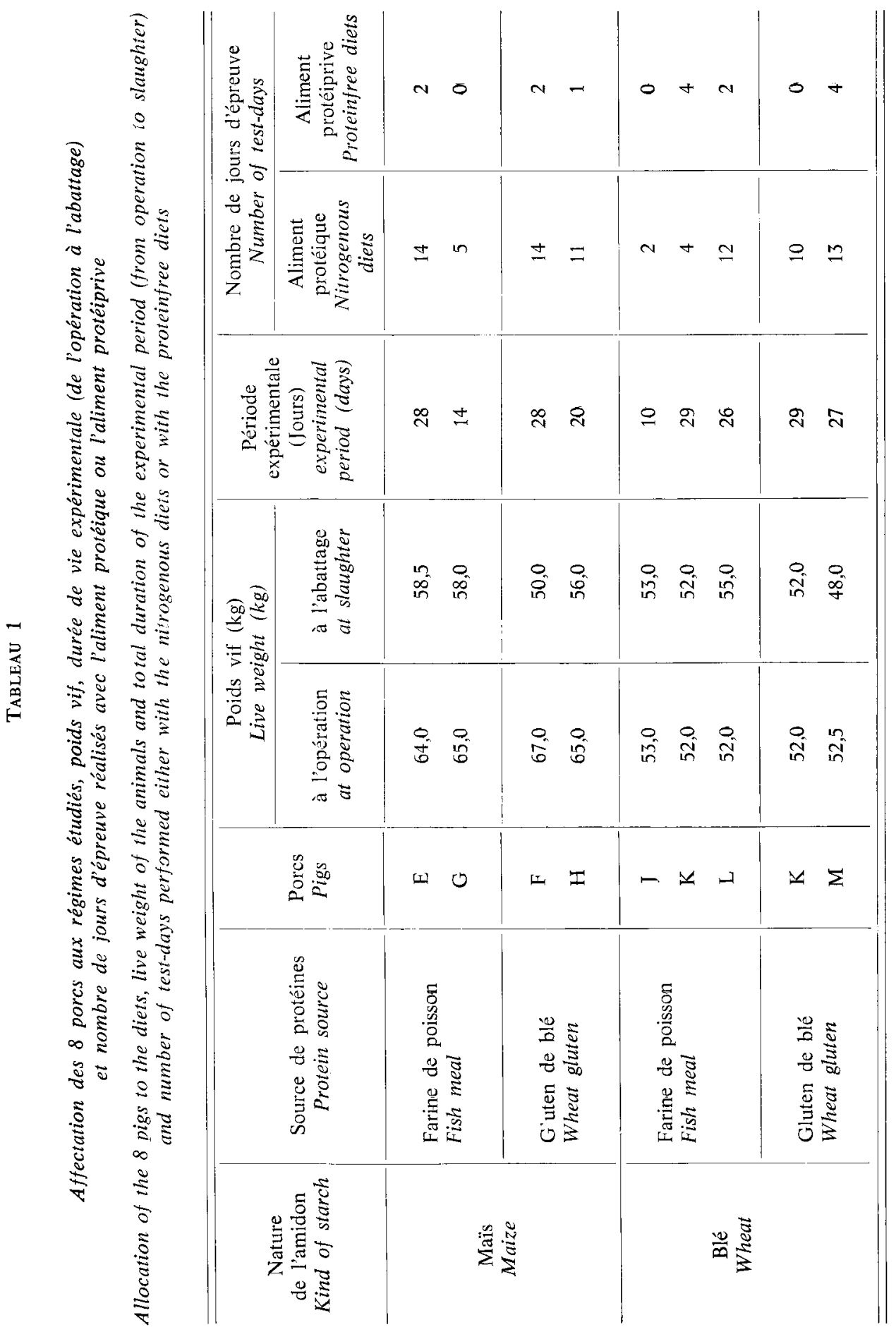




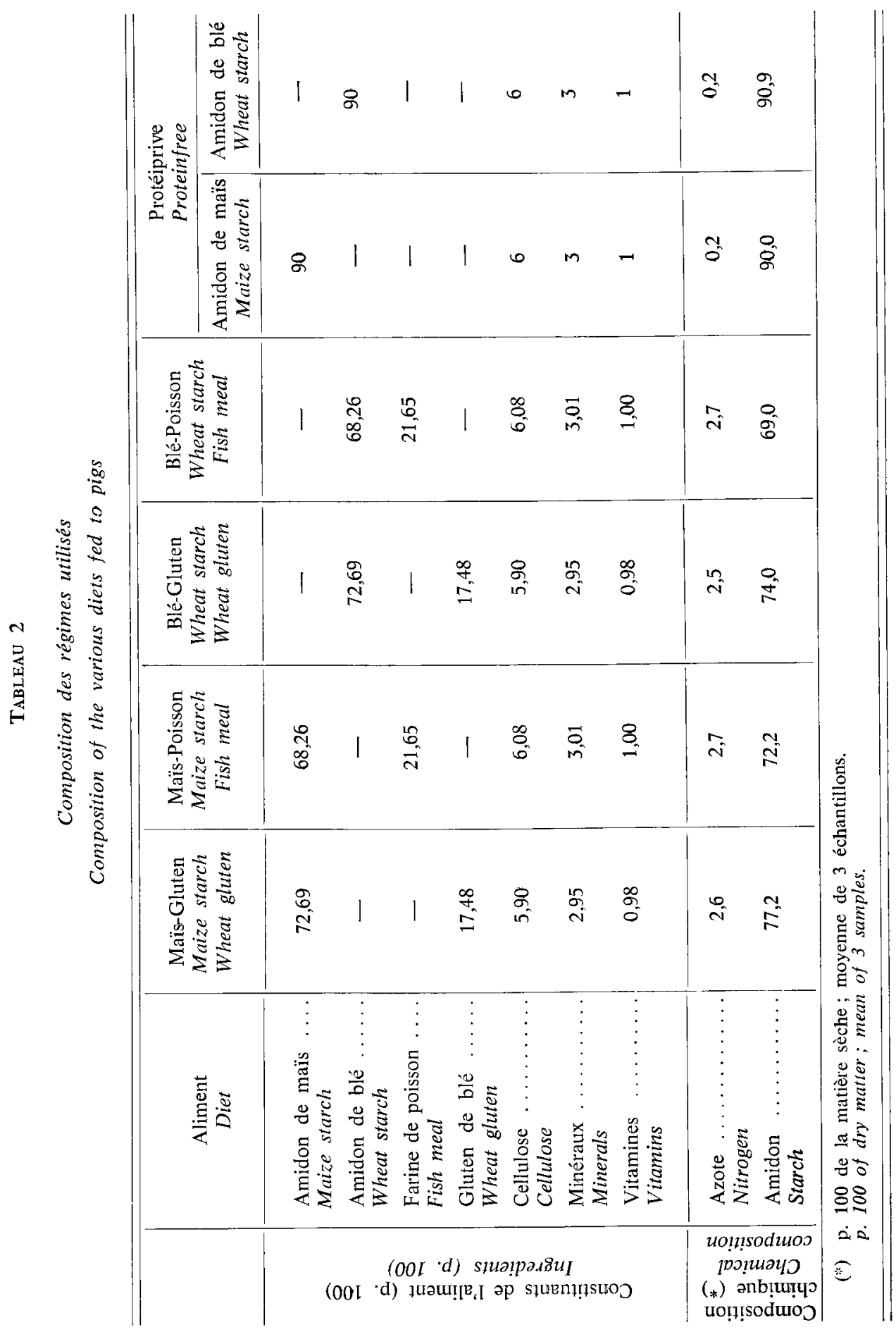




\section{4. - Echantillonnage et analyse des digesta}

On enregistre, pour chaque période de collecte définie par la chronologie précisée plus haut, le volume et le poids frais des digesta recueillis. Les contenus sont homogénéisés par agitation vigoureuse. On prélève une fraction de poids constant (environ $80 \mathrm{~g}$ de matière fraîche). Après lyophilisation, une partie de l'échantillon est utilisée pour la détermination de la teneur en matière sèche $\left(24\right.$ heures à l'étuve à $\left.104^{\circ} \mathrm{C}\right)$. Le reste de l'échantillon lyophilisé est utilisé pour la détermination de l'amidon et de l'azote total des contenus digestifs. Un second prélèvement d'environ $40 \mathrm{~g}$ de matière fraîche est réalisé en plus, pour un petit nombre de nycthémères seulement. Cet échantillon est centrifugé (2500 g - $20 \mathrm{mn}$ ). Le surnageant est utilisé pour la détermination de l'azote soluble.

L'amidon des contenus digestifs recueillis est défini comme l'ensemble du glucose et de tous ses polymères $\alpha$, dosés selon la technique décrite par CuBER \& LAPlace (1979). L'azote, total ou soluble selon le cas, est déterminé par la méthode KJELDAHL. Tous les résultats relatifs aux quantités de matières azotées sont calculés en grammes d'azote, tel que mesuré par la méthode KJELDAHL, et non en matières azotées totales (azote affecté du coefficient 6,25), en raison de la différence importante entre les 2 sources protéiques utilisées, et par analogie avec le mode d'expression usuel (ZebrowsKa, 1973 ; Holmes ; Bayley \& Horney, 1973 ; Holmes et al., 1974 ; Low, 1979).

\section{5. - Mode d'expression et d'exploitation des résultats}

Tous les résultats sont exprimés en pourcentage des quantités ingérées correspondantes sauf l'azote soluble qui est rapporté à l'azote total ingéré. Toutes les informations obtenues sont présentées, sur la base des valeurs moyennes, séparément pour chacune des deux étapes de réalisation de l'expérience (maïs puis blé). La comparaison de ces données ainsi que celle des régimes protéiprives maïs et blé sont assurées par un test de $\mathrm{T}$ de Student.

L'ensemble des résultats obtenus pour les quatre régimes azotés définis par le plan d'expérience fait l'objet d'une analyse factorielle réalisée à l'aide du programme MODLI (KoBILINSKY, 1980) d'analyse de la variance, mis en œuvre sur un calculateur MITRA 125 (1), qui autorise l'exploitation de dispositifs non orthogonaux. Les facteurs de variation pris en compte isolément dans le modèle sont au nombre de trois : la nature de l'amidon (à 2 niveaux : blé et maïs), la source de protéines (à 2 niveaux : poisson et gluten) et la répétition des repas d'épreuve pour un même régime (de 2 à 14 essais selon les cas - voir tableau 1). Ce dernier effet est dénommé par commodité «effet nycthémère ». L'effet individu ne peut être isolé, un même porc n'ayant pas été soumis à tous les régimes. Cet «effet porc» est identifiable seulement à l'intérieur d'un groupe de données obtenues pour un même régime; il est donc assimilable à l'interaction d'ordre 3 : amidon-protéine-porc. Les interactions d'ordre 2 sont en conséquence les suivantes : amidon-protéine, amidon-nycthémère, nycthémère-protéine. Les interactions d'ordre 3 sont d'une part l'interaction amidon-protéine-nycthémère, et d'autre part l'interaction amidon-protéine-porc désignée dans le texte sous le vocable «effet porc». Enfin, la résiduelle correspond à l'interaction d'ordre 4 : amidon-protéine-nycthémère-porc.

(1) Laboratoire de Biométrie, I.N.R.A., C.N.R.A., 78000 Versailles. 


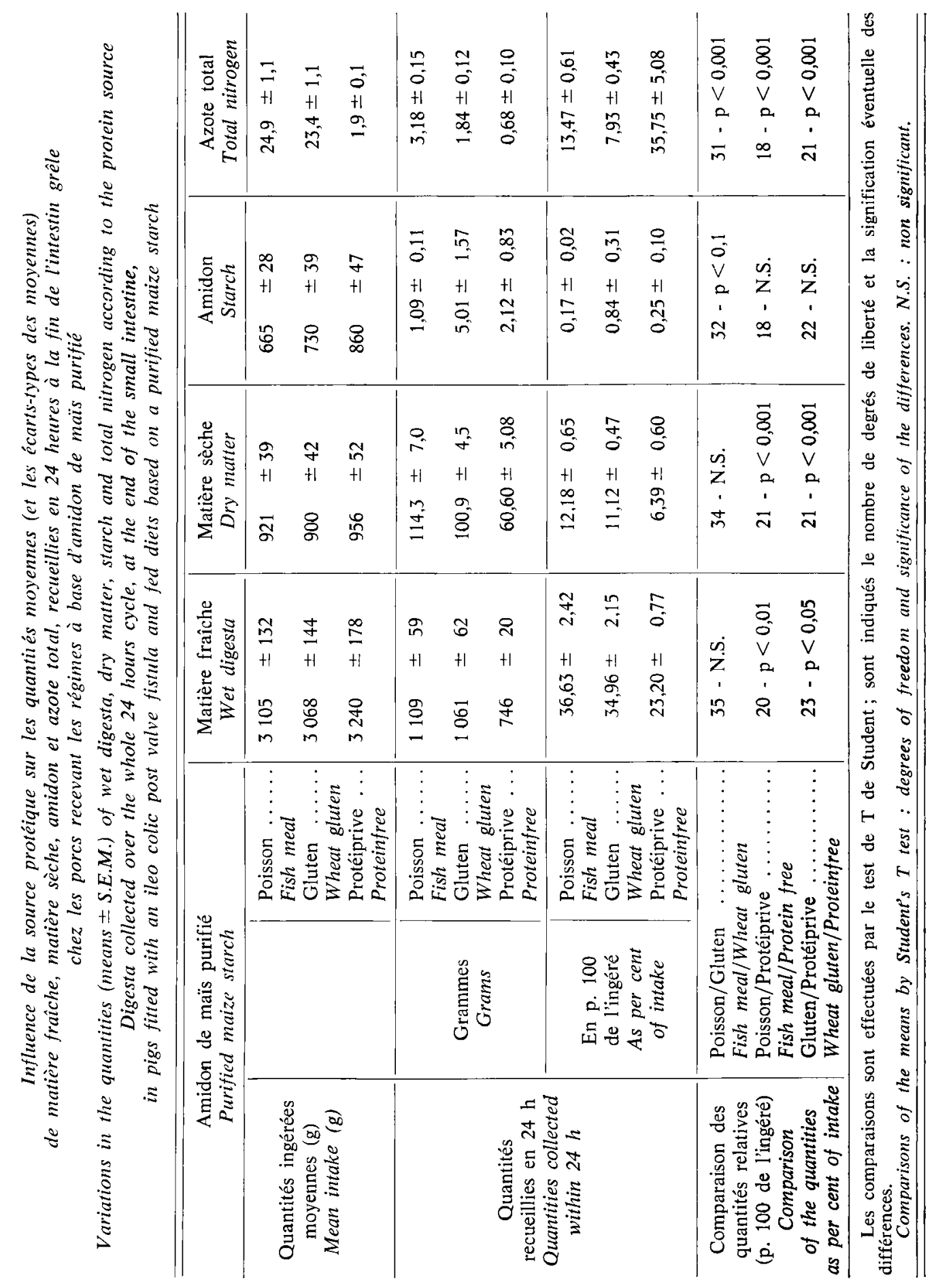


Ce mode d'exploitation a été appliqué aux quatre variables contrôlées (quantités de matière fraîche, matière sèche, amidon et azote total, exprimées en p. 100 des quantités ingérées) pour chacune des 6 collectes réalisées dans la journée et pour l'échantillon représentatif de l'ensemble du nycthémère d'épreuve.

\section{Résultats}

\section{1. - Digestion des aliments à base d'amidon de maïs purifié}

\section{a) Matière fraîche}

La quantité totale de matière fraîche recueillie en $24 \mathrm{~h}$ à la suite d'un repas d'épreuve représente (tabl. 3) approximativement le tiers de la quantité ingérée au total (farine + eau de dilution). Cependant, à la suite de l'ingestion d'un régime protéiprive, la quantité collectée en $24 \mathrm{~h}$ est, à ingéré égal, significativement plus faible qu'après ingestion de l'un ou l'autre des régimes azotés. Cette différence correspond au cumul de différences non significatives entre régimes protéiprives et régimes azotés pour chacune des collectes successives effectuées dans les 24 heures (fig. 1), à l'exception de la collecte nocturne (quatorzième à vingt-quatrième heure postprandiale). Les quantités recueillies à chaque temps de la cinétique sont toujours analogues pour les régimes azotés, quelle que soit la source protéique.

Cette similitude entre les 2 régimes azotés est retrouvée au plan de la cinétique (fig. 2), avec début de l'émission de matière fraîche correspondant au repas d'épreuve au-delà de la quatrième heure postprandiale, et débit maximum au cours des septième et huitième heures. Le débit de matière fraîche décroît ensuite progressivement, plus précocement dans le cas de l'aliment poisson que dans le cas de l'aliment gluten (fig. 2). Dans le cas du régime protéiprive, le débit maximum est enregistré au cours des cinquième et sixième heures, l'essentiel de la matière fraîche ayant franchi la jonction iléo-caeco-colique alentour de la douzième heure.

\section{b) Matière sèche}

Pour quelques $900 \mathrm{~g}$ de matière sèche ingérée, ce sont approximativement $100 \mathrm{~g}$ de matière sèche qui sont recueillis en $24 \mathrm{~h}$. Cependant, pour une même quantité ingérée, la quantité totale de matière sèche collectée en $24 \mathrm{~h}$ est significativement plus faible après ingestion d'aliment protéiprive qu'après ingestion de l'un ou l'autre des régimes azotés qui fournissent des valeurs analogues (tabl. 3). La teneur moyenne en matière sèche des collectes de $24 \mathrm{~h}$ est significativement plus faible lors de l'ingestion du régime protéiprive $(8,12 \pm 0,61 \mathrm{p}$. 100) que lors de l'ingestion des régimes poisson $(10,34 \pm 0,25$ p. $100 ;$ p $<0,001)$ ou gluten $(9,60 \pm 0,38$ p. $100 ; p<0,10)$. Les teneurs moyennes en matière sèche, enregistrées pour ces régimes poisson et gluten, diffèrent également entre elles au seuil 10 p. 100 .

L'examen des quantités recueillies à chacun des temps de la cinétique (fig. 1) met en évidence une arrivée plus précoce de la matière sèche pour le régime poisson (débit maximum : septième - huitième heures) que pour le régime gluten (débit maximum : neuvième - dixième heures). Dans le cas de l'aliment protéiprive, le débit de matière sèche reste relativement stable de la quatrième à la dixième heure postprandiale. Pour les 3 aliments, l'essentiel de la matière sèche franchit la jonction iléo-caeco-colique entre la quatrième et la douzième heures postprandiales (fig. 2). Au-delà de la dixième heure postprandiale, les quantités résiduelles de matière sèche parvenant à la fin de l'intestin grêle sont significativement plus faibles lors de l'ingestion de l'aliment protéiprive (fig. 1). 


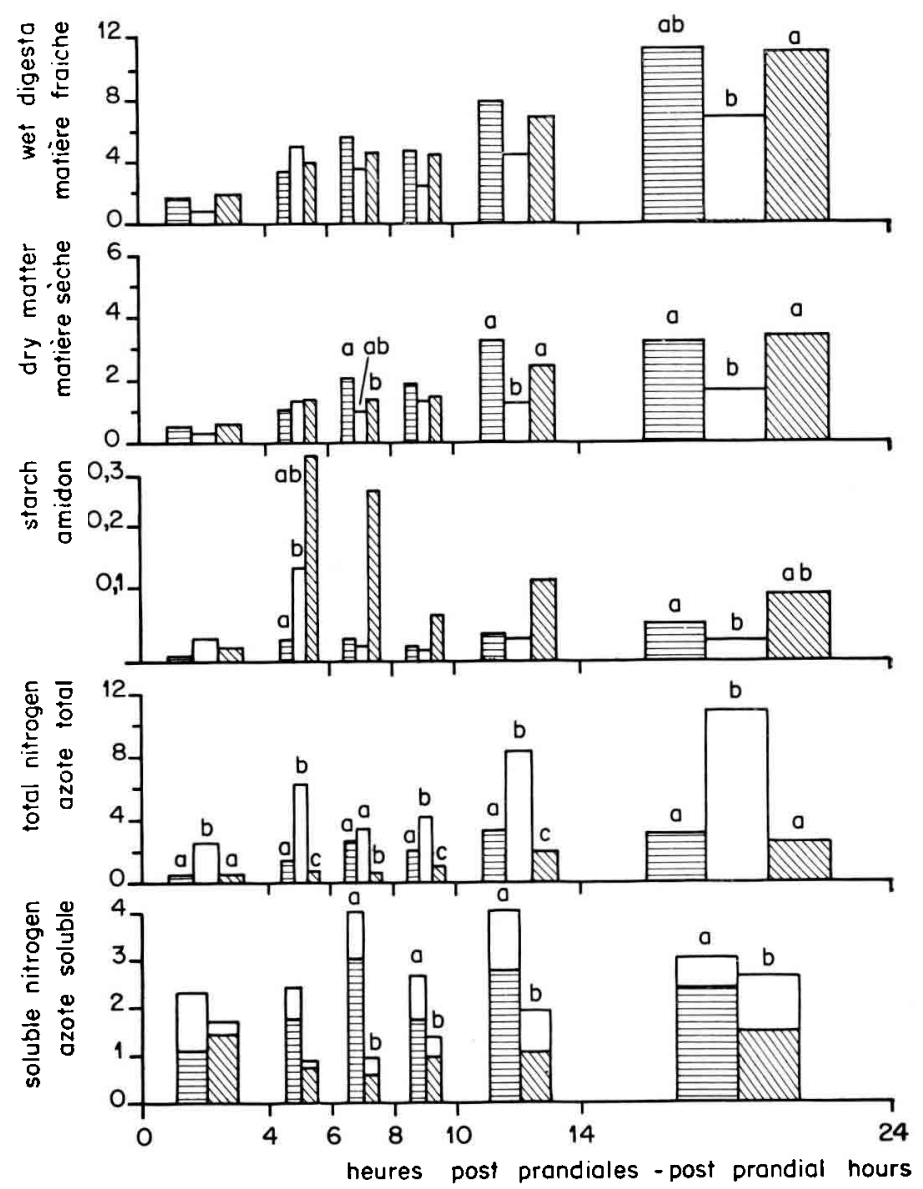

FIG. 1

Quantités moyennes de matière fraîche, matière sèche, amidon, azote total et azote soluble collectées à l'extrémité distale de l'intestin grêle,

après un repas d'épreuve à base d'amidon de maïs purifié,

selon la source protéique du régime : farine de poisson (hâchures horizontales),

gluten de blé (hâciures obliques) on régime protéiprive (colonnes blanches)

Mean quantities of wet digesta, dry matter, starch, total nitrogen, collected at the distal end of the small intestine in pigs fitted with an ileo colic post valve fistula

and fed a test-meal based on a purified maize starch, according to the dietary protein scurce :

fish meal (horizontal bars), wheat gluten (oblique bars)

or protein-free diet (white columns)

Chaque groupe de colonnes correspond à l'une des périodes consécutives de collecte : 0 à 4 heures, 4 à 6 heures, 6 à 8 heures, 8 à 10 heures, 10 à 14 heures et 14 à 24 heures après le repas. Les quantités recueillies sont exprimées en pourcentage des quantités ingérées correspondantes.

En ce qui concerne l'azote soluble, exprimé en pourcentage des quantités d'azote total ingéré, la quantité collectée est indiquée par la partie hachurée de la colonne. Cette dernière représente la quantité d'azote total dans les échantillons pour lesquels a été mesuré l'azote soluble.

Les lettres surmontant les colonnes expriment les différences entre moyennes (test de $\mathrm{T}$ de Student) pour une même période de collecte : les colonnes surmontées de lettres différentes, diffèrent significativement entre elles.

Each group of columns illustrates one of the consecutive collection periods : 0 io 4 hours, 4 to 6 hours, 6 to 8 hours, 8 to 10 hours, 10 to 14 hours and 14 to 24 hours after the test meal. The collected quantities are expressed as per cent of the corresponding ingested quantities.

As regards soluble nitrogen, expressed as per cent of total nitrogen intake, the collected quantity is shown by the hatched part of the column. The whole column shows the corresponding quantity of total nitrogen in the samples used for soluble nitrogen determination.

Within each group, the columns bearing different letters significantly differ according to Student's T test. 


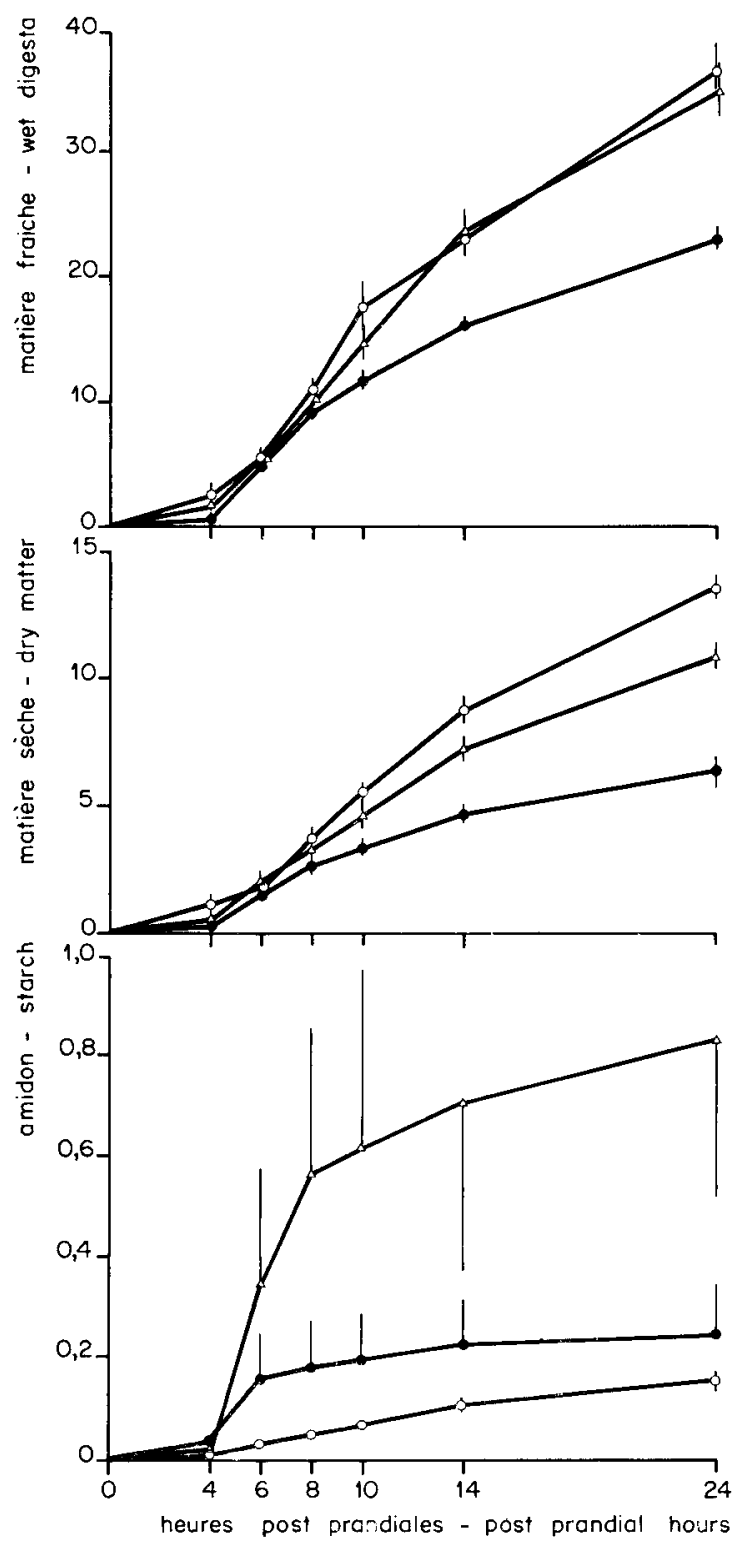

FIG. 2

Evolution comparée, selon la source protéique du régime, des quantités cumulées moyennes de matière fraîche, matière sèche et amidon collectées à l'extrémité distale de l'intestin grêle durant 24 heures après un repas d'épreuve à base d'amidon de maïs purifié

Comparative evolution, according to the dietary protein source,

of the mean cumulated quantities of wet digesta, dry matter and starch collected at the distal end of the small intestine, during 24 hours after a test mal based on a purified maize starch, in pigs fitted with an ileo colic post valve fistula

Ces quantités sont exprimées en p. 100 des quantités ingérées correspondantes.

These quantities are expressed as per cent of the respective ingested quantities.

F Farine de poisson.

Fish meal. $\triangle$ Gluten de blé. Wheat gluten.
- Régime protéiprive. Protein free diet. 
c) Amidon

La quasi totalité de l'amidon ingéré est digérée et absorbée dans l'intestin grêle. Cependant, la quantité résiduelle est significativement plus élevée pour le régime gluten que pour le régime poisson; une valeur intermédiaire est enregistrée pour le régime protéiprive (tabl. 3). Cette particularité observée pour le régime gluten est retrouvée pour la plupart des collectes successives dans les 24 heures (fig. 1). Toutefois, les écarts enregistrés à chacun des temps de collecte ne sont pas toujours significatifs en raison de l'extrême variabilité des quantités résiduelles d'amidon, d'une épreuve à l'autre, lors de l'ingestion du régime gluten (fig. 2). L'essentiel de ces faibles quantités résiduelles d'amidon est recueilli au cours des cinquième à huitième heures pour l'aliment gluten et au cours des cinquième et sixième heures pour l'aliment protéiprive. Dans le cas de l'aliment poisson des quantités quasi négligeables sont retrouvées régulièrement au-delà de la quatrième heure postprandiale.

\section{d) Azote}

La quantité totale d'azote recueillie en $24 \mathrm{~h}$ est significativement plus importante lors d'ingestion de l'aliment poisson que lors d'ingestion de l'aliment gluten (tabl. 3). Cette différence est retrouvée pour chacune des collectes intervenues entre la cinquième et la quatorzième heure postprandiale (fig. 1). Après un repas protéiprive, la quantité d'azote collectée en $24 \mathrm{~h}$, exprimée en pourcentage de la faible quantité ingérée (moins de $2 \mathrm{~g}$ d'azote), est elle-même beaucoup plus élevée que celle enregistrée pour les régimes azotés (tabl. 3). Il en est de même à chacun des temps de la cinétique (fig. 1). Exprimée en g d'azote, cette quantité recueillie en $24 \mathrm{~h}$ après un repas protéiprive n'équivaut cependant qu'au tiers de celle mesurée après un repas de l'aliment gluten.

Au plan de la cinétique (fig. $3 \mathrm{~A}$ ), la plus grande partie de l'azote total est collectée entre la cinquième et la quatorzième heure postprandiale, y compris lors d'ingestion d'un régime protéiprive. Par ailleurs, un pic de débit est observé aux septième-huitième heures pour le régime poisson, ou aux cinquième-sixième heures pour le régime protéiprive, alors qu'un débit relativement régulier est enregistré pour le régime gluten.

Alors que la proportion d'azote soluble dans l'azote total ingéré est très différente selon la source protéique (31,6 p. 100 dans le cas du poisson contre 2,3 p. 100 dans le cas du gluten), les proportions correspondantes d'azote soluble dans l'azote total des digesta collectés en 24 heures ne sont pas significativement différentes $(75,5$ p. 100 dans le cas de repas d'aliment poisson, contre 60,0 p. 100 dans le cas de repas d'aliment gluten). Cela étant, la quantité totale d'azote soluble collectée en 24 heures pour un régime poisson est significativement supérieure à celle qui est recueillie dans le cas d'un régime gluten (tabl. 4). On note cependant que cette différence des quantités d'azote soluble collectées, selon la source protéique ingérée, n'est significative qu'au-delà de la sixième heure postprandiale pour les collectes successives au cours des 24 heures (fig. 1). La cinétique de passage de l'azote soluble est illustrée, comparativement à celle de l'azote total et pour chacune des deux sources protéiques dans la figure $3 \mathrm{~B}$. 


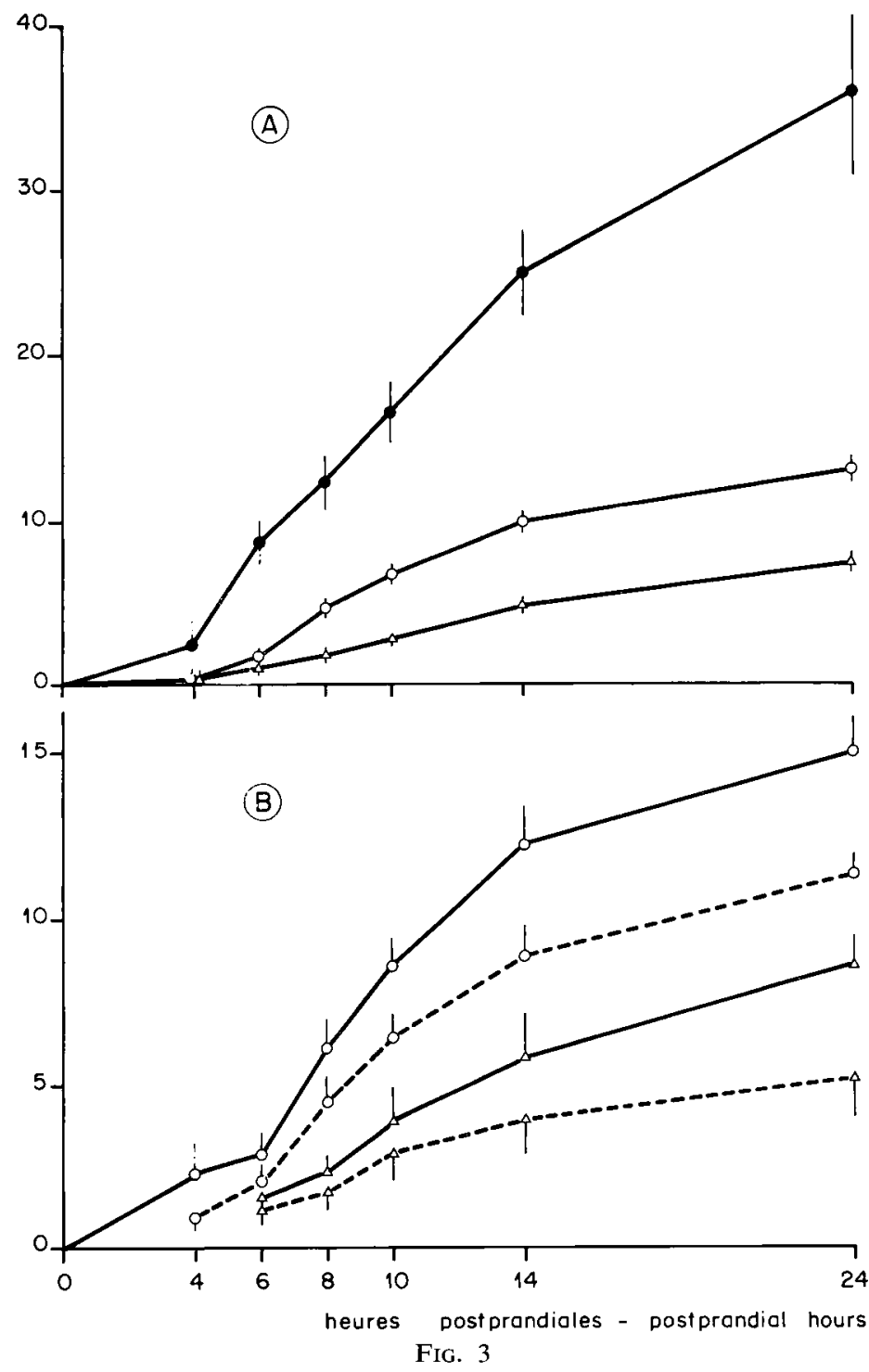

Evolution comparée, selon la source protéique du régime,

des quantités cumulées moyennes d'azote collectćes à l'extrémité distale de l'intestin grêle durant 24 heures après un repas d'épreuve à base d'amidon de maïs purifié

Comparative evolution, according to the dietary protein source, of the mean cumulated quantities of nitrogen collected at the distal end of the small intestine, during 24 hours after a test meal based on a purified maize starch, in pigs, fitted with an ileo colic post valve fistula

En A : Quantités cumulées d'azote total, en p. 100 des quantités d'azote total ingérées, pour l'ensemble des nycthémères d'épreuve.

En B : Quantités cumulées d'azote soluble (ligne pointillée), et d'azote total (trait continu) pour ceux des nycthémères d'épreuve pour lesquels a été déterminé l'azote soluble. Ces quantités sont exprimées dans les deux cas en p. 100 des quantités d'azote total ingérées.

Top graph A: Cumulated quantitic's of total nitrogen, as per cent of the total nitrogen intake, on the basis of all the test-days.

Bottom graph $B$ : Cumulated quantities of soluble nitrogen (dotted line) and of total nitrogen (straight line) on the basis of the test-days with soluble nitrogen determination. Both quantities are expressed as per cent of the total nitrogen intake.

- Farine de poisson. $\triangle$ Gluten de blé. Fish meal.

$\triangle \quad$ Gluten de blé.
- Régime protéiprive.

Protein free diet. 


\section{TABLEAU 4}

Influence de la source protéique sur les quantités movennes (et les écarts-types des moyennes) d'azote soluble, et d'azote total pour les mêmes nycthémères que ceux au cours desquels a été mesuré l'azote soluble

$V$ ariations in the quantities (means \pm S.E.M.) of soluble and total nitrogen, during the same test-days, according to the protein source

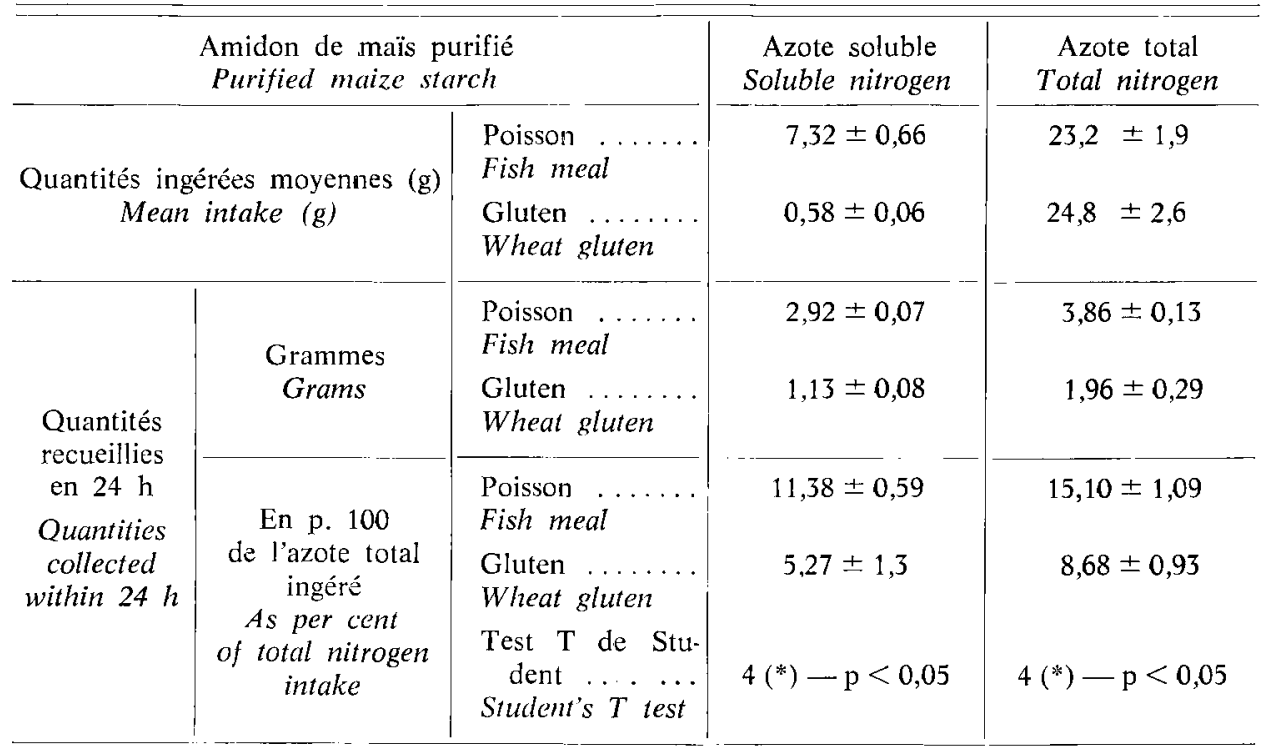

Digesta recueillis en 24 heures à la fin de l'intestin grêle chez les porcs recevant les régimes à base d'amidon de maïs purifié.

Digesta collected over the whole $24 \mathrm{~h}$ cycle, at the end of the small intestine, in pigs fitted with an ileo colic post valve fistula and fed diets based on a purified maize starch.

$\left({ }^{*}\right)$ Nombre de degrés de liberté. Degrees of freedom.

\section{2. - Digestion des aliments à base d'amidon de blé purifié}

\section{a) Matière frâlche}

La quantité totale de matière fraîche recueillie en $24 \mathrm{~h}$ à la suite d'un repas d'épreuve représente (tabl. 5) près de la moitié de la quantité ingérée au total (farine + eau de dilution) dans le cas de l'aliment poisson. Par contre, elle n'en représente qu'environ un tiers pour les régimes gluten et protéiprive (tabl. 5). Une quantité supérieure pour le régime poisson, est aussi observée pour la plupart des collectes successives effectuées dans les 24 heures bien que la différence ne soit pas nécessairement significative dans tous les cas (fig. 4). Les quantités de matière fraîche recueillies pour les régimes gluten et protéiprive ne diffèrent jamais significativement entre elles (fig. 4). Indépendamment de ces aspects quantitatifs, la cinétique de passage de la matière fraîche au niveau de la jonction iléo-caeco-colique est analogue pour les 3 aliments à base de blé (fig. 5). L'émission de l'essentiel de la matière fraîche correspondant au repas d'épreuve débute à la quatrième heure postprandiale 
et se prolonge jusqu'à la quatorzième heure. Dans cet intervalle de temps, le débit de matière fraîche par période de 2 heures est relativement stable dans le cas de l'aliment poisson, soit environ 6 p. 100 de la matière fraîche ingérée. Par contre, le débit de matière fraîche pour les régimes gluten et protéiprive n'atteint ce niveau (6 p. 100 en 2 h) qu'au cours des neuvième-dixième heures.

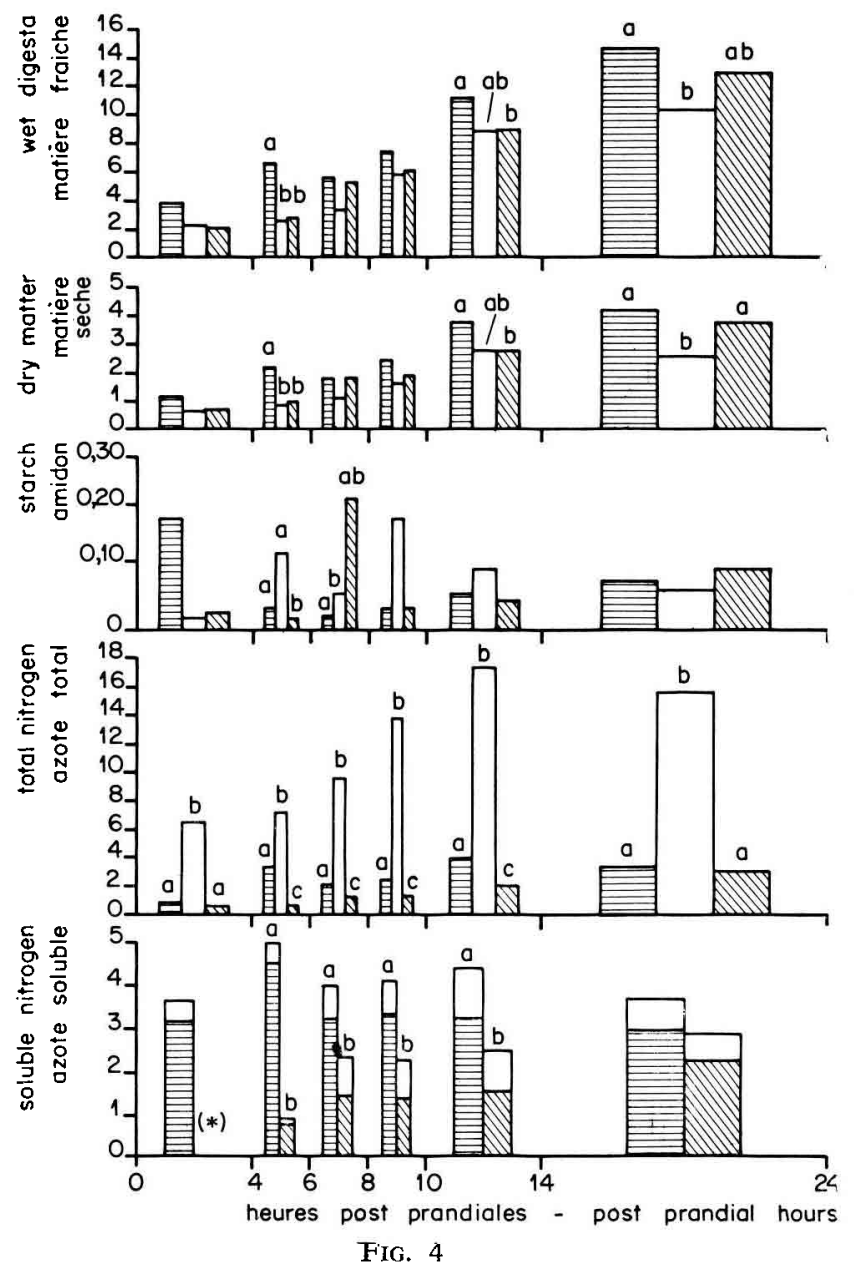

Quantités moyennes de matière fraîche, matière sèche, amidon, azote total et azote soluble collectées à l'extrémité distale de l'intestin grêle selon la source protéique entrant dans la composition d'un régime à base d'amidon de blé purifié

Mean quantities of wet digesta, dry matter, starch, total nitrogen and soluble nitrogen, collected at the distal end of the small intestine according to the protein source included into a diet based on a purified wheat starch

Le principe de cette figure est par ailleurs en tous points identique à celui de la figure 1 .

(*) Mesure non effectuée par défaut de substrat.

The principle of this figure does not anywise differ from that used in figure 1.

(*) Lacking measurement due to insufficient quantity of digesta. 


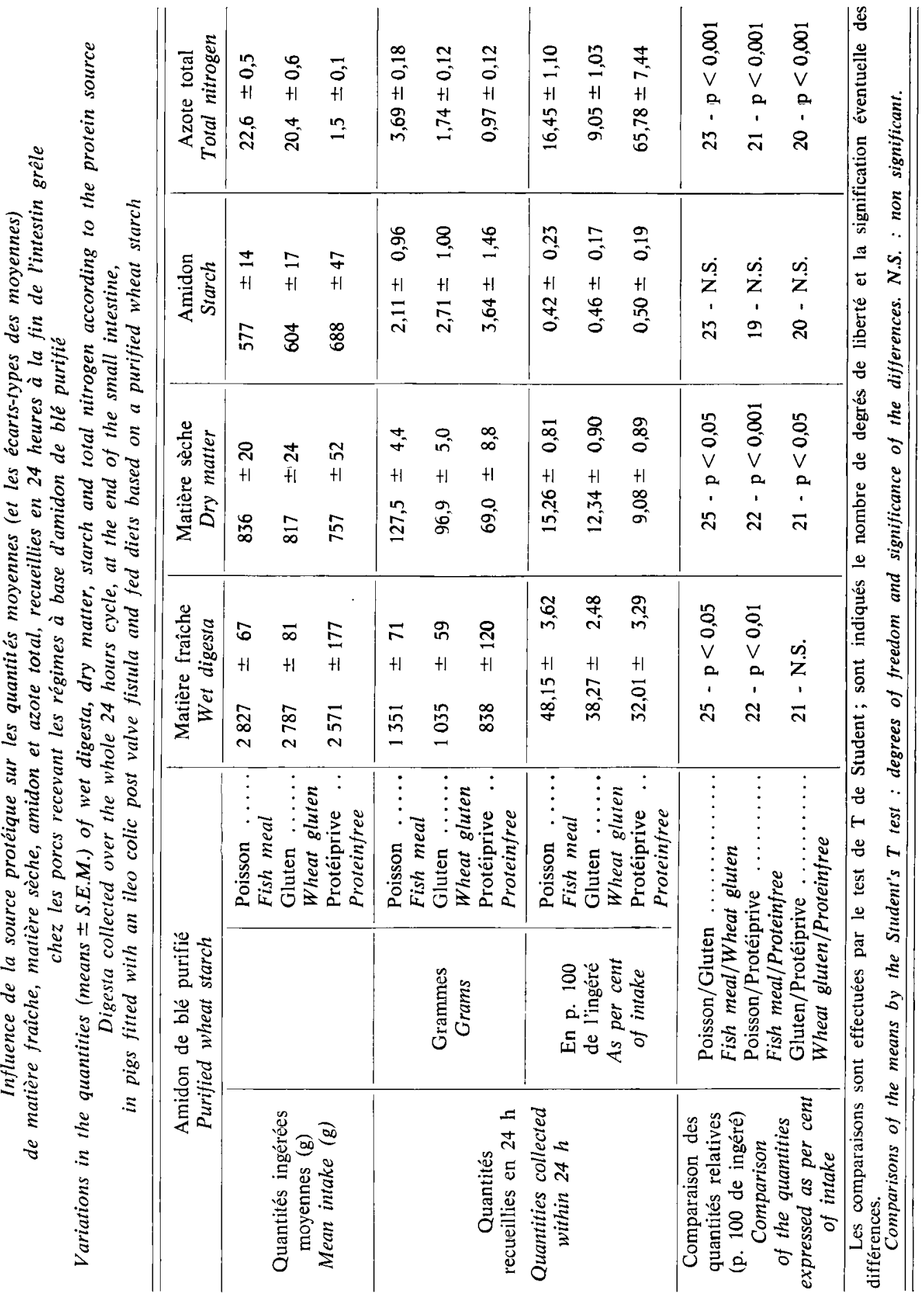




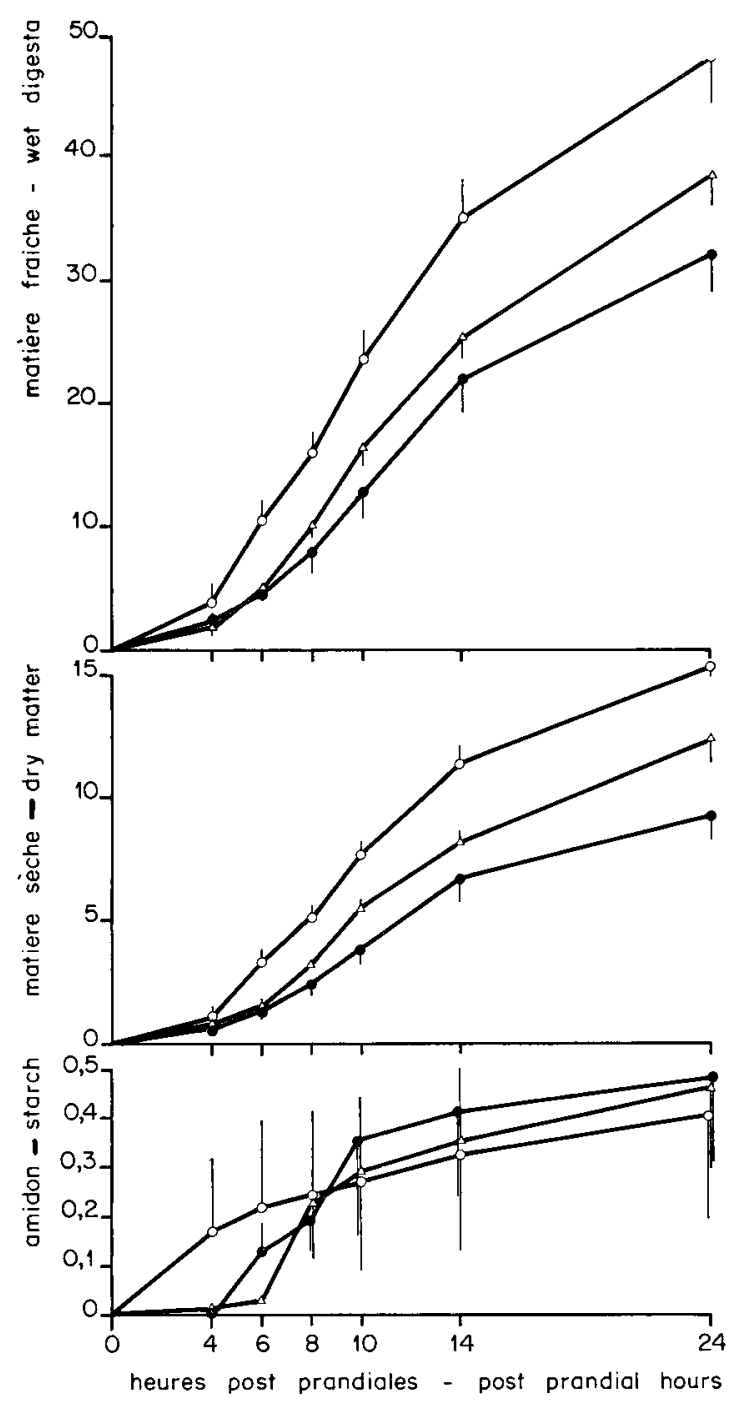

FIG. 5

Evolution comparée, selon la source protéique du régime, des quantités cumulées moyennes de matière fraîche, matière sèche et amidon collectées à l'extrémité distale de lintestin grêle durant 24 heures après un repas d'épreuve à base d'amidon de blé purifié

Comparative evolution, according to the dietary protein source,

of the mean cumulated quantities of wet digesta, dry matter, and starch collected at the distal end of the small intestine, during 24 hours after a test meal based on a purified wheat starch diet, in pigs fitted with an ileo colic post valve fistula

Ces quantités sont exprimées en p. 100 des quantités ingérées correspondantes.

These quantities are expressed as per cent of the corresponding ingested quantities.
- Farine de poisson.
$\triangle$ Gluten de blé.
Fish meal.
Wheat gluten.
- Régime protéiprive. Protein free diet. 


\section{b) Matière sèche}

La matière sèche résiduelle totale en 24 heures est significativement différente pour chacun des trois régimes (tabl. 5), la quantité la plus élevée étant obtenue pour le régime poisson et la plus faible pour laliment protéiprive. La teneur moyenne en matière sèche des collectes de $24 \mathrm{~h}$ est de l'ordre de 9 p. 100 pour les trois régimes à base de blé.

L'examen des quantités recueillies pour chacune des collectes au cours des $24 \mathrm{~h}$ (fig. 4) et de la cinétique de passage (fig. 5) montre que l'essentiel de la matière sèche du repas d'épreuve franchit la jonction iléo-caeco-colique entre la quatrième et la quatorzième heure postprandiale pour les trois régimes. Toutefois, un débit maximum en $2 \mathrm{~h}$ équivalant à environ 2 p. 100 de la matière sèche ingérée est observé pour une seule collecte (neuvième et dixième heures) dans le cas de l'aliment protéiprive, pour deux collectes consécutives (septième à dixième heures) dans le cas de l'aliment gluten, et pour trois collectes consécutives (cinquième à dixième heures) dans le cas de l'aliment poisson.

\section{c) Amidon}

L'amidon résiduel total en $24 \mathrm{~h}$, à la fin de l'intestin grêle, est analogue pour les trois aliments à base de blé et représente au plus 0,5 p. 100 de la quantité d'amidon ingérée (tabl. 5).

Dans tous les cas, la digestion très complète de l'amidon de blé, ainsi que la variabilité entre animaux et entre jours d'épreuve (fig. 4 et 5) interdisent d'établir une cinétique ayant une véritable signification. Ainsi, la forte quantité moyenne d'amidon collectée à la quatrième heure postprandiale dans le cas du régime poisson résulte d'un petit nombre de valeurs élevées obtenues chez un même animal. Tout au plus, on peut noter que l'essentiel de cette faible quantité d'amidon résiduel atteint l'extrémité distale de l'intestin grêle en $10 \mathrm{~h}$ après le repas.

\section{d) Azote}

La quantité totale d'azote recueillie en $24 \mathrm{~h}$ est significativement plus importante lors de l'ingestion de l'aliment poisson que lors de celle de l'aliment gluten (tabl. 5). Cette différence est retrouvée pour chacune des collectes intervenues entre la cinquième et la quatorzième heure postprandiale (fig. 4). Après un repas protéiprive, la quantité d'azote collectée en $24 \mathrm{~h}$ et exprimée en pourcentage de la quantité ingérée est elle-même beaucoup plus élevée que celle enregistrée pour les régimes azotés. Il en est de même à tous les temps de la cinétique (fig. 4). Toutefois, exprimée en $g$ d'azote, cette quantité recueillie en $24 \mathrm{~h}$ après un repas protéiprive ne représente guère plus de la moitié de celle mesurée pour l'aliment gluten.

La plus grande partie de l'azote total est collectée entre la cinquième et la quatorzième heure postprandiale, y compris pour le régime protéiprive (fig. $6 \mathrm{~A}$ ). Le débit maximum d'azote total est observé (fig. 4) aux cinquième-sixième heures pour l'aliment poisson et aux neuvième-dixième heures pour l'aliment protéiprive. Par contre, un débit relativement régulier est enregistré pour l'aliment gluten.

La proportion d'azote soluble dans l'azote total des digesta collectés en $24 \mathrm{~h}$ ne diffère pas significativement $(78,5$ p. 100 pour le régime poisson contre 65 p. 100 
pour le régime gluten), contrairement à ce qui est observé dans les aliments cux-mêmes (poisson : 30,9 - gluten : 2,4 p. 100). La quantité totale d'azote soluble collectée en 24 heures pour le régime poisson est significativement supérieure à celle recueillie dans le cas du régime gluten (tabl. 6). Cette différence des quantités d'azote soluble collectées, selon la source protéique ingérée, est vérifiée pour chacune des collectes de la cinquième à la quatorzième heure (fig. 4). La cinétique de passage de l'azote soluble est illustrée, comparativement à celle de l'azote total et pour chacune des deux sources protéiques dans la figure $6 \mathrm{~B}$.

\section{TABLeau 6}

Influence de la source protéique sur les quantités moyennes (et les écarts-types des moyennes) d'azote soluble, et d'azote total

pour les mêmes nycthémères que ceux au cours desquels a été mesuré l'azote soluble

Variations in the quantities (mcans \pm S.E.M.) of soluble and total nitrogen, during the same test-days, according to the protein source

\begin{tabular}{|c|c|c|c|c|}
\hline \multicolumn{3}{|c|}{$\begin{array}{l}\text { Amidon de blé purifié } \\
\text { Purified wheat starch }\end{array}$} & $\begin{array}{l}\text { Azote soluble } \\
\text { Soluble nitrogen }\end{array}$ & $\begin{array}{c}\text { Azote total } \\
\text { Total nitrogen }\end{array}$ \\
\hline \multicolumn{2}{|c|}{$\begin{array}{l}\text { Quantités ingérées moyennes }(\mathrm{g}) \\
\text { Mean intake }(\mathrm{g})\end{array}$} & $\begin{array}{l}\text { Poisson ....... } \\
\text { Fish meal } \\
\text { Gluten ........ } \\
\text { Wheat gluten }\end{array}$ & $\begin{array}{l}6,83 \pm 0,27 \\
0,49 \pm 0,02\end{array}$ & $\begin{array}{l}22,1 \pm 0,9 \\
20,1 \pm 1,0\end{array}$ \\
\hline \multirow{2}{*}{$\begin{array}{c}\text { Quantités } \\
\text { recueillies } \\
\text { en } 24 \mathrm{~h} \\
\text { Quantities } \\
\text { collected } \\
\text { within } 24 \mathrm{~h} .\end{array}$} & $\begin{array}{l}\text { Grammes } \\
\text { Grams }\end{array}$ & $\begin{array}{l}\text { Poisson ....... } \\
\text { Fish meal } \\
\text { Gluten ......... } \\
\text { Wheat gluten }\end{array}$ & $\begin{array}{l}3,24 \pm 0,19 \\
1,22 \pm 0,06\end{array}$ & $\begin{array}{l}4,12 \pm 0,23 \\
1,84 \pm 0,20\end{array}$ \\
\hline & $\begin{array}{c}\text { En p. } 100 \\
\text { de l'azote } \\
\text { total ingéré } \\
\text { As per cent } \\
\text { of total nitrogen } \\
\text { intake }\end{array}$ & $\begin{array}{l}\text { Poisson ....... } \\
\text { Fish meal } \\
\text { Gluten ......... } \\
\text { Wheat gluten } \\
\text { Test de T de Stu- } \\
\quad \text { dent ........ } \\
\text { Student's T test }\end{array}$ & $\begin{array}{r}14,78 \pm 1,12 \\
6,56 \pm 0,70\end{array}$ & $\begin{array}{l}18,81 \pm 1,40 \\
10,03 \pm 1,69\end{array}$ \\
\hline
\end{tabular}

Digesta recueillis en 24 heures à la fin de l'intestin grêle chez les porcs recevant les régimes à base d'amidon de blé purifié.

Digesta collected over the whole $24 \mathrm{~h}$ cycle, at the end of the small intestine, in pigs fitted with an ileo colic post valve fistula and fed diets based on a purified wheat starch.

$(*)$ Nombre de degrés de liberté. Degrees of freedom.

\section{3. - Régimes azotés : analyse de variance}

a) Les facteurs isolés : amidon, protéine, nycthémère

La nature de l'amidon, la source de protéines ou le nycthémère d'épreuve sont sans effet significatif à l'égard des quantités de matière fraîche collectée. En ce 

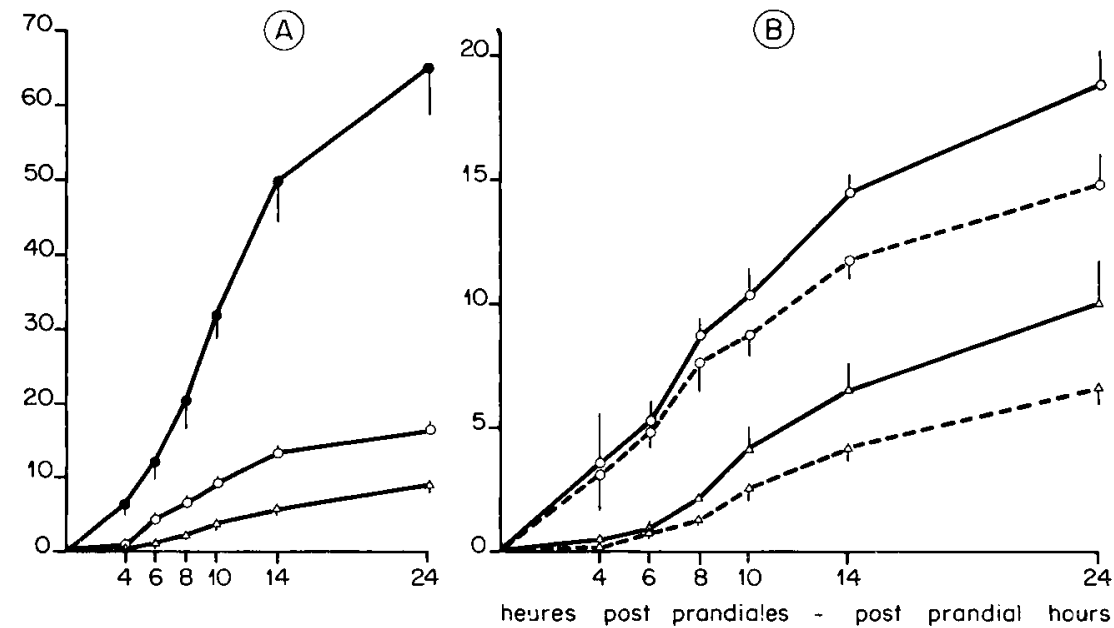

FIG. 6

Evolution comparée, selon la source protéique du régime,

des quantités cumulées moyennes d'azote collectées à l'extrémité distale de l'intestin grêle durant 24 heures après un repas d'épreuve à base d'amidon de blé purifié

Comparative evolution, according to the dietary protein source,

of the mean cumulated quantities of nitrogen collected at the distal end of the small intestine, during 24 hours after a test meal based on a purified wheat starch, in pigs fitted with an ileo colic post valve fistula

Le principe de cette figure est en tous points identique à celui de la figure 3 .

The principle of this figure does not anywise differ from that used in figure 3.

qui concerne la matière sèche, seule la source de protéines exerce une influence significative : la quantité de matière sèche recueillie pour les régimes poisson est significativement plus élevée que celle obtenue pour les régimes gluten lors de la collecte à la quatorzième heure $(F=14,1-p<0,01)$, et pour la collecte totale des 24 heures $(F=4,8-p<0,05)$.

La quantité d'amidon collectée est significativement influencée par les 3 facteurs (amidon, protéine, nycthémère) pour les collectes effectuées à la sixième et à la dixième heure (tabl. 7). Mais, seul l'effet protéine affecte significativement la quantité d'amidon recueillie en 24 heures. L'effet amidon correspond à une quantité d'amidon collectée plus élevée en régime maïs. L'effet protéine à l'égard de l'amidon collecté se traduit par une plus grande quantité d'amidon résiduel en régime gluten. L'effet nycthémère souligne pour deux des six collectes de la journée, l'existence occasionnelle de quantités d'amidon supérieures à la moyenne certains jours d'épreuve.

En ce qui concerne les quantités d'azote total collecté (tabl. 7), l'effet amidon, significatif pour la collecte à la sixième heure et pour la collecte totale des 24 heures, traduit l'obtention de quantités d'azote total plus élevées pour les régimes blé. Un effet protéine important est constaté pour la plupart des échantillons et au total en 24 heures, la quantité d'azote collectée étant toujours plus importante pour les régimes poisson. Aucun effet nycthémère n'est enregistré à l'égard de la quantité d'azote total. 


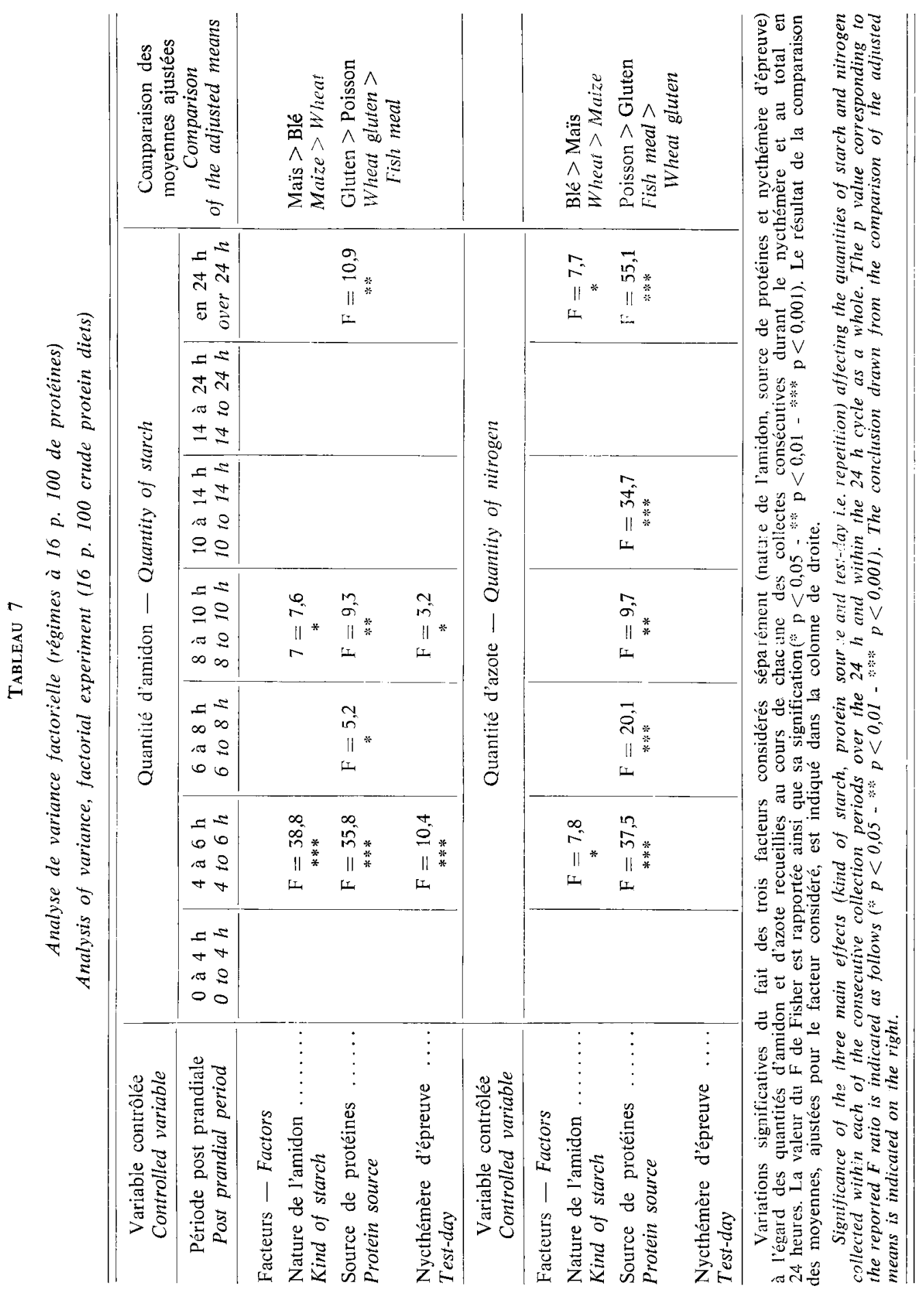




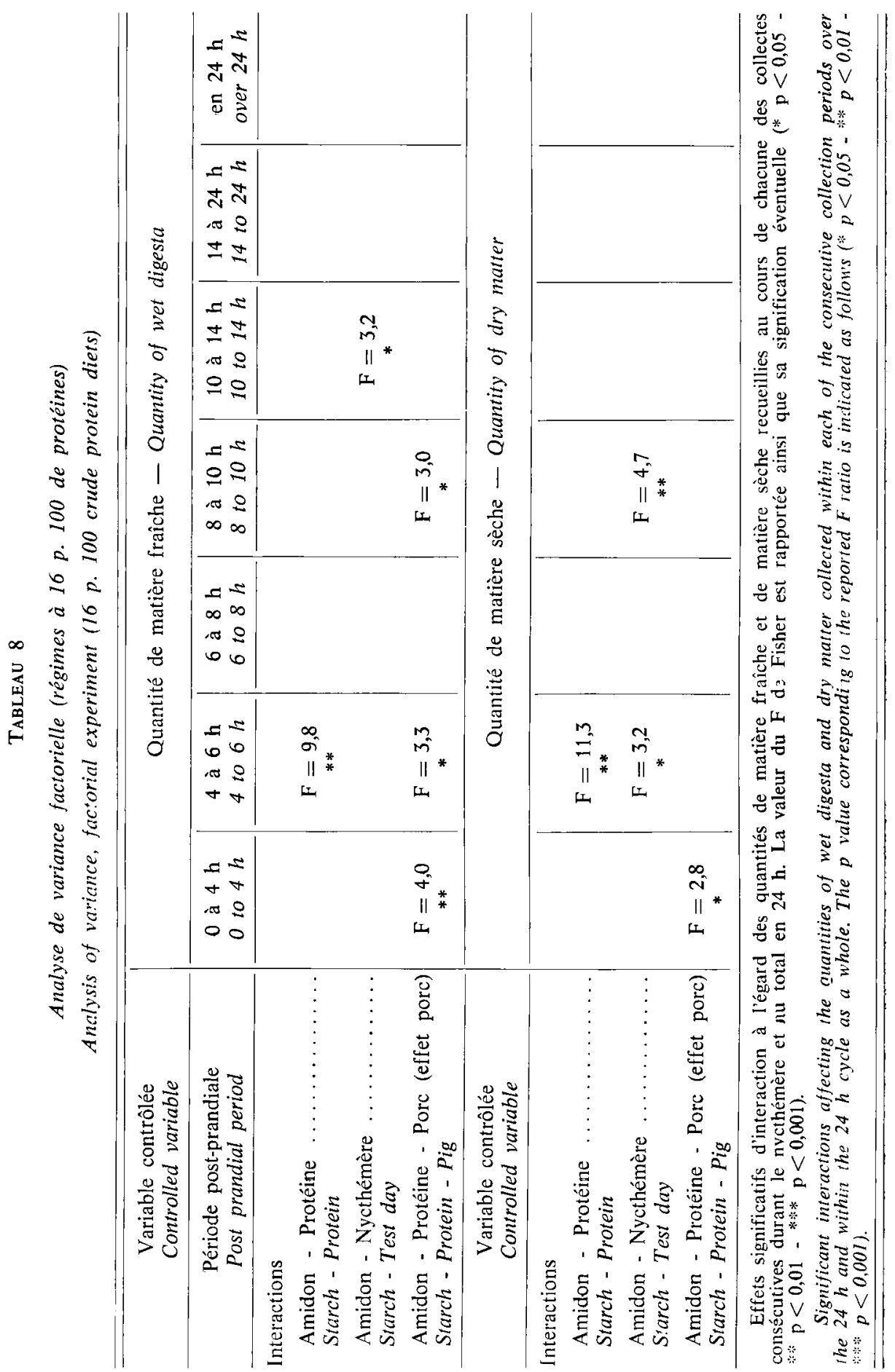




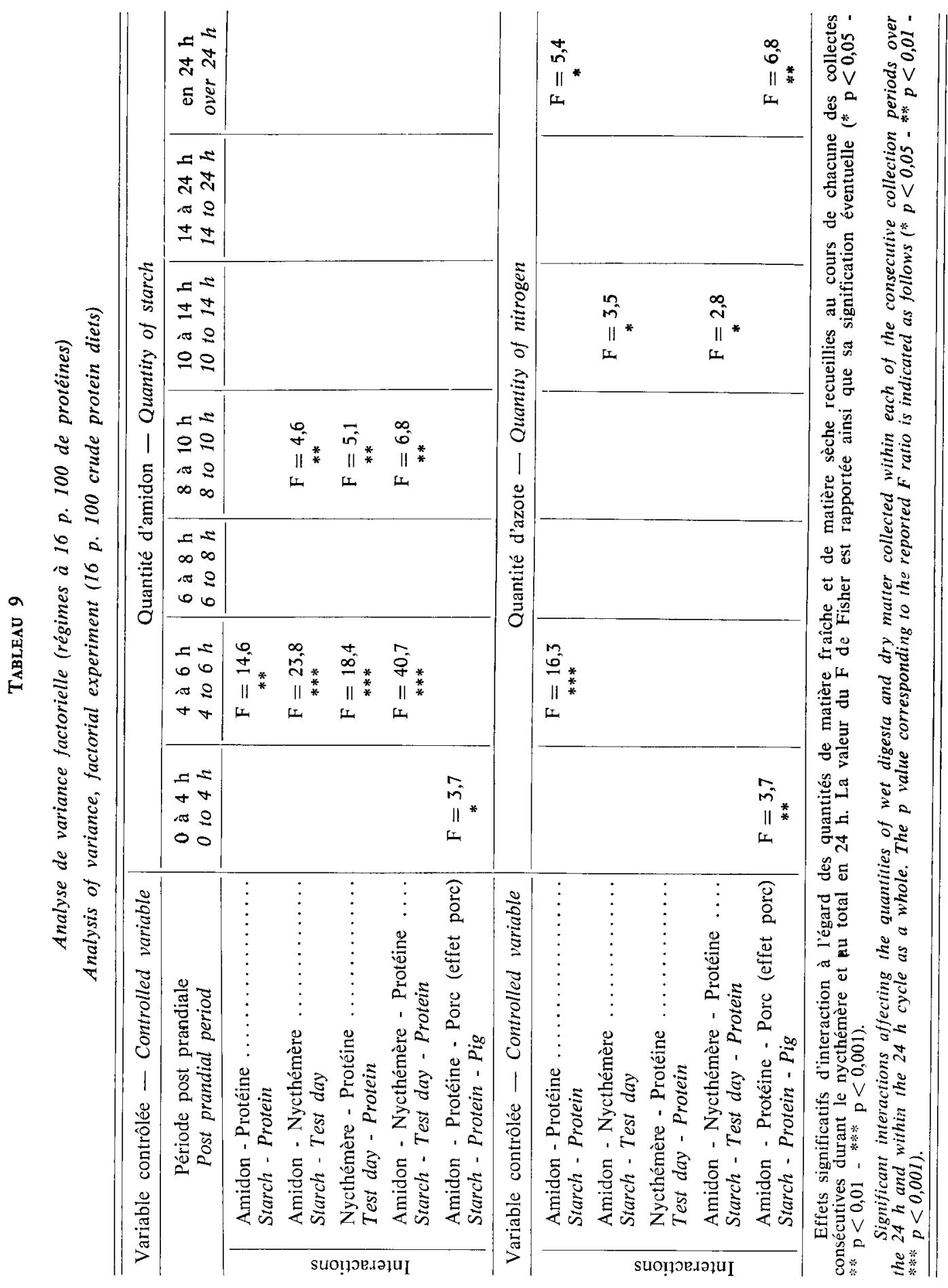




\section{b) Effets d'interaction}

Aucune influence significative des interactions nycthémère-protéine ou amidonnycthémère-protéine n'est enregistrée à l'égard des quantités de matière fraîche et de matière sèche. Les seuls effets significatifs d'interaction à l'égard de ces deux variables sont indiqués dans le tableau 8. Ils sont limités à certaines des collectes réalisées au cours des 24 heures, et en particulier pour la collecte effectuée à la sixième heure. L'effet d'interaction amidon-protéine se traduit par une quantité moyenne ajustée de matière frâiche et de matière sèche particulièrement faible dans le cas du régime maïs-poisson. L'effet d'interaction amidon-nycthémère correspond à des quantités plus faibles le premier jour d'épreuve en régime maïs. Enfin, l'interaction d'ordre 3 assimilée à l'effet porc répond des quantités élevées de contenus frais et secs recueillies chez le porc J.

Toutes les interactions testées, à l'exception de l'effet porc, sont significatives à l'égard des quantités d'amidon recueillies lors des collectes aux sixième et dixième heures (tabl. 9) mais aucun effet significatif n'est enregistré à l'égard des collectes en 24 heures. L'interaction amidon-protéine, pour la collecte à la sixième heure, est liée, comme pour la matière frâiche et la matière sèche, aux quantités moyennes ajustées plus faibles d'amidon recueillies en régime maïs-poisson. Pour toutes les interactions prenant en compte l'effet nycthémère, l'effet significatif est lié aux quantités occasionnellement élevées d'amidon recueillies lors de certaines épreuves. Aucun nycthémère ou groupe particulier de nycthémères n'est systématiquement responsable de ces effets. Enfin, comme pour la matière fraîche et la matière sèche, l'effet porc sur la quantité d'amidon recueillie au cours des 4 premières heures est le fait du porc $J$.

En ce qui concerne la quantité d'azote (tabl. 9), les effets d'interaction significatifs enregistrés pour certaines des collectes au cours de la journée relèvent des mêmes causes que dans le cas de l'amidon, détaillé ci-dessus. Cependant, la quantité d'azote collectée au total en 24 heures est soumise à une interaction significative entre amidon et protéine. Cette quantité est plus importante en régime poisson qu'en régime gluten et plus élevée en régime blé qu'en régime maïs (voir effets isolés au tableau 7). Mais l'existence de l'interaction amidon-protéine fait que l'effet de la protéine poisson est renforcé dans le cas d'association avec le blé par rapport au maïs et que l'effet blé est renforcé dans le cas d'association avec le poisson par rapport au gluten. Enfin, la quantité d'azote collectée en 24 heures est soumise à une interaction amidon-protéine-porc significative, qui résulte des valeurs enregistrées chez deux porcs ( $J$ et $L$ ) qui se trouvent être les animaux affectés au régime blé-poisson. Cette dernière interaction ne fait donc que confirmer l'interaction amidon-protéine ci-dessus mentionnée.

\section{4. - Comparaison des régimes protéiprives}

Les quantités de matière fraîche recueillies après ingestion de l'aliment protéiprive blé (fig. 4) sont plus élevées $(\mathrm{p}<0,10)$ que dans le cas de l'aliment protéiprive maïs (fig. 1) lors des collectes effectuées aux dixième, quatorzième et vingt-quatrième heures ainsi que pour l'ensemble des 24 heures (tabl. 3 et 5). Un effet de même sens est observé en ce qui concerne la matière sèche collectée de la quinzième à la vingt-quatrième heure et pour l'ensemble des 24 heures $(p<0,10)$. Il n'existe pas 
de différence significative, à aucun temps de collecte, entre les quantités d'amidon obtenues selon le type d'aliment protéiprive. Les quantités d'azote recueillies aux huitième et dixième heures sont plus élevées (respectivement $\mathrm{p}<0,10$ et $\mathrm{p}<0,05$ ) lors d'ingestion de l'aliment protéiprive blé. Il en est de même $(\mathrm{p}<0,05)$ pour l'ensemble des 24 heures.

\section{Discussion}

\section{1. - Aspects méthodologiques}

Le poids vif initial des animaux utilisés pour chacune des deux séries, $65 \mathrm{~kg}$ en moyenne dans le cas du maïs contre $52 \mathrm{~kg}$ dans le cas du blé, est relativement différent. Cependant cette inégalité reste a priori sans conséquence grave dans la mesure où il n'y a pas, au-delà du sevrage, d'évolution systématique, avec l'âge, de la digestibilité apparente. Au demeurant, la fourchette de poids de l'ensemble des animaux a été rapidement réduite. En effet, les conditions limitatives d'alimentation imposées (un seul repas quotidien) sont responsables, selon l'aliment, d'un arrêt de croissance voire d'importantes pertes de poids. On peut noter dans le tableau 1 que celles-ci sont plus sévères chez les porcs recevant du maïs par rapport au blé et qu'elles sont plus marquées pour les régimes gluten que pour les régimes poisson. La restriction du fait du repas unique aurait en principe pu être évitée en distribuant aux porcs 2 ou 3 repas quotidiens, dont un repas d'épreuve marqué. Cependant les marqueurs n'offrent qu'une fiabilité illusoire en raison de leur migration différentielle par rapport aux digesta, comme l'ont montré Guilioteau et Toullec (1980) pour l'oxyde de chrome dont le débit de sortie n'est que faiblement corrélé aux débits de matière fraîche, matière sèche et azote. De plus, la question de l'association préférentielle d'un marqueur à l'un ou l'autre des constituants de la matière sèche (amidon, azote...) reste sans réponse.

En dépit des inconvénients mentionnés ci-dessus, les conditions de réalisation de l'expérience peuvent être considérées comme satisfaisantes. Aucun effet du facteur jour d'épreuve n'a été observé à l'égard des quantités reculeillies en 24 heures de l'une ou l'autre fraction des digesta. Ceci témoigne d'une bonne répétabilité d'une preuve à l'autre, quel que soit laliment, en l'absence d'évolution systématique des préparations animales utiiscées. De la même façon, il n'y a pas d'effet d'interaction significatif amidon-nycthémère, ou nycthémère-protéine sur les quantités collectées en 24 heures. Il n'y a donc pas d'évolution systématique dans le temps de la digestibilité apparente des régimes, liée à la nature de l'amidon ou à la source de protéines. Cet ensemble de faits témoigne de la stabilité des conditions de déroulement de l'expérience.

Une dernière question d'ordre méthodologique concerne l'éventualité d'une transformation des digesta entre le moment de leur émission dans le ballon de collecte, et le moment de l'échantillonnage. L'absence d'une telle interférence a été vérifiée au cours d'essais complémentaires. Les teneurs en azote et en amidon de la matière sèche, recueillie soit dans le ballon soit dans un récipient réfrigéré au fur et à mesure de son émission, pour les mêmes heures du nycthémère et le même régime, chez le même animal, ne diffèrent pas significativement. Par conséquent, les informations analytiques obtenues peuvent être considérées comme réellement représentatives de la composition des digesta émis vers le gros intestin. 


\section{2. - Cinétique de passage des digesta}

Pour tous les régimes azotés ou protéiprives, l'essentiel des quantités de matière fraîche, matière sèche, amidon, ou azote est toujours collecté entre la quatrième et la quatorzième heure postprandiale. Les faibles différences éventuellement observées sur ces limites de temps sont difficilement interprétables étant donné l'espacement des collectes ( 2 ou 4 h). Cependant, on constate quau cours de cette période d'émission, le profil du débit de digesta varie selon le régime : le débit passe par un véritable maximum ou reste relativement stable pendant tout ou partie de la période d'émission. Mais ces variations du profil de débit échappent à toute systématisation et il n'est pas possible de discerner une quelconque relation entre les rythmes d'évacuation gastro-duodénale (LAPLACE et al., 1981) et de passage à la jonction iléo-caeco-colique pour les mêmes régimes. Cette dissociation peut être expliquée par l'importance des fonctions propres de lintestin grêle : modalités du transfert des digesta (LAPLACE ct Roman, 1979), disparition par absorption de certaines fractions et addition par les apports endogènes.

En définitive, les informations cinétiques apportées dans ce travail sont nécessairement limitées à une description du profil de passage des digesta à la fin de l'intestin grêle. Ce profil est variable en fonction du régime. Il existe aussi, entre essais, une certaine variabilité du début et de la fin du passage de l'essentiel des matériaux d'un repas. Cette variabilité est à rapprocher de l'incertitude qui pèse sur des temps de rétention 0 et 100 p. 100, et se trouve accentuée par l'espacement des collectes. Ce double phénomène est probablement responsable du nombre d'effets significatifs enregistrés pour divers facteurs ou leurs interaction à l'égard des collectes réalisées à la sixième heure d'une part et aux dixième et quatorzièmes heures d'autre part. Cela est d'autant plus évident que la fraction concernée est en quantité plus faible. L'illustration en est apportée par la variabilité des quantités d'amidon enregistrées dans les collectes aux sixième et dixième heures (tabl. 9). En conséquence, l'évaluation de la digestion dans l'intestin grêle ne peut être valablement fondée que sur des bilans au terme des 24 heures après un repas d'épreuve. Ces bilans échappent en effet à toute variabilité entre essais (absence d'effet nycthémère ou d'interactions impliquant cet effet).

\section{3. - Bilan de la digestion : matière frầche, matière sèche}

Globalement, au terme de lanalyse de variance concernant les régimes azotés, la quantité de matière frấche recueillie à la fin de l'intestin grêle ne fait l'objet d'aucune variation du fait de la nature de l'amidon, de la source protéique, ou d'une quelconque interaction impliquant l'un de ces facteurs. Cependant, si l'on considère séparément les régimes blé, la quantité de matière fraîche recueillic lors de l'association au gluten est plus faible que pour la combinaison blé-poisson. Dans le cas des régimes maïs, une quantité de matière fraîche analogue est recueillic pour nos régimes poisson ou gluten, de même que pour les régimes maïs-soja ou maïs-colza utilisés par Holmes et al. (1974).

En ce qui concerne la matière sèche, l'analyse de variance globale met en évidence un effet protéine significatif, la quantité recueillie étant plus élevée pour les régimes poisson que pour les régimes gluten. Cette différence peut être reliée à deux faits : la plus grande digestibilité des protéines du gluten; la proportion plus importante d'un amidon très digestible dans les régimes gluten. Par ailleurs, cet 
écart selon la source protéique, important dans le cas des régimes blé (tabl. 5), reste limité dans le cas des régimes maïs (tabl. 3). Une différence de digestibilité apparente de la matière sèche selon la source protéique (meilleure pour le gluten que pour le poisson dans notre expérience) est également observée par Holmes et al., (1974) selon que les protéines sont apportées par du tourteau de soja ou du tourteau de colza.

Dans le cas des régimes protéiprives, les quantités de matière fraîche et de matière sèche collectées en 24 heures sont plus élevées pour le blé que pour le maïs. Ceci revient à dire que la digestibilité de la matière sèche est moins bonne lors de l'ingestion d'amidon de blé. Cette différence, en situation protéiprive, est à opposer à l'absence d'effet amidon à l'égard de la matière sèche dans le cas des régimes azotés.

D’une façon générale, les quantités de matière fraîche et de matière sèche collectées en régime protéiprive sont toujours inférieures à celles recueillies avec les régimes azotés correspondants, quoique la différence ne soit pas significative pour la matière fraîche entre blé protéiprive et blé-gluten. La digestibilité plus élevée de la matière sèche en régime protéiprive s'explique principalement par le fait que l'amidon a une digestibilité plus élevée que les protéines. Ces phénomènes enregistrés en régime protéiprive sont également observés par ZEBrowsKa et al. (1975) comparativement à un aliment «standard» ou un aliment comportant de la caséine. De même, Holmes et al. (1974) recueillent en $24 \mathrm{~h}$ des quantités de matière fraîche qui sont 2,5 fois plus faibles pour le régime protéiprive que pour leurs régimes azotés (comportant du tourteau de soja ou de colza), et une digestibilité iléale apparente de la matière sèche de l'ordre de 81 p. 100 contre 66 à 72 p. 100 pour les régimes azotés. Nos résultats conduisent à calculer une digestibilité apparente de la matière sèche de 93,6 à 90,9 p. 100 respectivement pour le maïs et le blé protéiprives, contre 87,8 et 88,9 p. 100 (maïs-poisson et maïs-gluten) ou 84,7 et 87,7 p. 100 (blé-poisson et blé-gluten).

\section{4. - Bilan de la digestion : amidon, azote}

Les quantités d'amidon recueillies en $24 \mathrm{~h}$ sont très faibles $(0,17$ à 0,84 p. 100 de l'amidon ingéré), en accord avec les valeurs observées $(0,3$ à 0,6 p. 100) par IVAN \& FARRELL (1976) pour des régimes amidon de maïs purifié et caséine ou des régimes à base de blé. Les valeurs mentionnées ci-dessus pour des amidons de maïs purifiés sont plus faibles que celles enregistrées par Holmes, BAYLEY \& HoRNEY (1973) pour du maïs grain conservé sec ou humide ( 2 à 6 p. 100 de l'amidon ingéré). Cet écart pourrait être relié à la forme de présentation : maïs grain vs. amidon de maïs purifié. Par contre, les quantités d'amidon résiduelles dans le cas du blé sont analogues, qu'il soit apporté sous forme d'amidon purifié dans notre expérience ou sous forme de céréale broyée (IVAN \& Farrell, 1976). Ceci signifie probablement que l'amidon du grain de blé est plus « accessible» pour les enzymes digestives que celui du grain de maïs.

Le bilan de la digestion de l'amidon n'est pas influencé par la nature de l'amidon ingéré, pour les amidons concernés dans ce travail, aussi bien dans le cas des régimes azotés qu'en situation protéiprive. Les résultats de cette expérience ne confirment donc pas l'observation antérieure (DARCY, LAPLACE \& Villiers, 1980 b) d'une digestibilité apparente de l'amidon de blé légèrement supérieure $(+0,4$ p. 100) à celle de l'amidon de maïs pour des régimes à 16 p. 100 de protéines. Par ailleurs, 
la réduction de 5 p. 100 de la digestibilité de l'amidon enregistrée en régime protéiprive par rapport aux régimes azotés (DARCY, LAPLACE \& VILLIERS, 1980 b) n'est pas retrouvée non plus ici. Ces divergences résultent probablement d'aléas d'échantillonnage en raison d'une variabilité importante d'une épreuve à l'autre. Par contre, il existe un effet globalement très significatif de la source protéique sur la digestion de l'amidon : la digestibilité de l'amidon est meilleure lorsque les protéines sont apportées par du poisson. Cet effet est perceptible dans le cas du maïs $(99,83$ contre 99,16 p. 100) et quasi-négligeable dans le cas du blé $(99,58-99,54$ p. 100). De toute évidence, la digestion de l'amidon est pratiquement complète dans l'intestin grêle, et l'effet de la source protéique, quoique certain, reste négligeable eu égard à la nutrition de l'animal dans nos conditions expérimentales.

La digestibilité de l'azote total, à la fin de l'intestin grêle, fait l'objet de variations du fait de la nature de l'amidon, de la source protéique et de l'interaction entre ces deux facteurs. La digestibilité de l'azote total est meilleure pour les régimes gluten que pour les régimes poisson; elle est aussi meilleure pour les régimes maïs que pour les régimes blé. L'interaction de ces deux facteurs fait que cette digestibilité de l'azote est la plus mauvaise pour le régime blé-poisson et la meilleure pour le régime maïsgluten. On notera que les effets enregistrés à l'égard de la digestibilité de l'amidon d'une part et de l'azote d'autre part font que, pour un même amidon ingéré, si l'association avec l'une des deux protéines donne une meilleure digestibilité de l'azote, cette même association donnera aussi une moins bonne digestibilité de l'amidon qu'avec l'autre source protéique. Cette proposition est vérifiée, quelle que soit la nature de l'amidon ingéré.

Les résultats enregistrés pour nos différents régimes azotés peuvent être comparés (tabl. 10) aux diverses valeurs observées par d'autres auteurs, sous réserve des facteurs de variation intercurrents : diversité des autres constituants des aliments, variations de leurs teneurs, et traitements technologiques qui leur sont appliqués; techniques de fistulation et de collecte; modalités de détermination des bilans. Les valeurs obtenues pour les régimes poisson à base d'amidon purifié de maïs ou de blé $(86,5-83,6$ p. 100) sont supérieures à celle (75 p. 100) enregistrée par Low (1979) pour un régime associant la farine de poisson à des céréales : orge et blé. Nos digestibilités pour les régimes gluten $(92,1-90,9$ p. 100) sont analogues à celles enregistrées par Wunsche et al. (1979) pour du gluten de blé (92,6 p. 100) et par Low (1979) pour de la caséine $(91$ p. 100) incorporée à un régime purifié (amidon-saccharose). A noter qu'une valeur de 80 p. 100 seulement est constatée pour la caséine incorporée à un régime beaucoup plus complexe (ZebrowsKa, 1973). Cependant, dans les conditions particulières de ce dernier auteur, la digestibilité iléale de l'azote du régime gluten $(83$ p. 100) s'avère supérieure à celle de l'azote du régime caséine $(80$ p. 100).

Dans le cas des régimes protéiprives, les quantités limitées d'azote endogène recueillies représentent évidemment un pourcentage par rapport à l'azote ingéré beaucoup plus élevé que dans le cas des régimes azotés. Mais, il faut souligner que cette quantité d'azote endogène quittant l'intestin grêle est ici plus importante lors d'ingestion d'amidon de blé que lors d'ingestion d'amidon de maïs. Interprétée en termes de digestibilité, cette différence signifie une meilleure digestibilité apparente de l'azote en régime protéiprive lors d'ingestion d'amidon de maïs $(64,2$ p. 100) par rapport au blé (34,2 p. 100). Quelle qu'en soit l'origine (moindre production ou meilleure absorption d'azote endogène pour le régime maïs), cet écart peut rendre compte d'une partie au moins de l'effet amidon à l'égard de la digestibilité apparente de l'azote total en régime azoté. 


\section{TABLEAU 10}

Comparaison des valeurs de la digestibilité apparente iléale de l'azote total dans nos conditions expérimentales

à celles obtenues par d'autres auteurs pour diverses sources de protéines alimentaires

Comparison of the ileal apparent digestion coefficients for total nitrogen, in our experimental conditions,

to those recorded by other authors using various dietary protein sources

\begin{tabular}{|c|c|c|c|}
\hline $\begin{array}{l}\text { Taux protéique } \\
\text { du régime } \\
\text { (p. 100) } \\
\text { Dietary crude } \\
\text { protein level }\end{array}$ & $\begin{array}{c}\text { Source protéique } \\
\text { du régime } \\
\text { Dietary protein source }\end{array}$ & $\begin{array}{c}\text { Digestibilité } \\
\text { apparente iléale } \\
\text { de l'azote (p. 100) } \\
\text { Ileal apparent } \\
\text { digestibility } \\
\text { of nitrogen }\end{array}$ & $\begin{array}{l}\text { Auteurs } \\
\text { Authors }\end{array}$ \\
\hline 21 & $\begin{array}{l}\text { Tourteau de soja } \\
\text { Soya bean meal }\end{array}$ & 79,9 & \\
\hline 17 & $\begin{array}{l}\text { Tourteau de Colza } \\
\text { Rapeseed meal }\end{array}$ & 67,7 & $\begin{array}{l}\text { HolmEs et al. } \\
\text { (1974) }\end{array}$ \\
\hline 17 & Caséine - Casein & 89,5 & \multirow{3}{*}{$\begin{array}{c}\text { IVAN \& FARRELL } \\
(1976)\end{array}$} \\
\hline 17 & Blé dur - Hard wheat & 85,6 & \\
\hline 16 & Blé tenáre - Soft wheat & 80,4 & \\
\hline 15 & $\begin{array}{l}\text { Tourteau d'arachide } \\
\text { Groundnut meal }\end{array}$ & 78,0 & \multirow{3}{*}{ Low (1979) } \\
\hline 15 & Caséine - Casein & 91,0 & \\
\hline 15 & Poisson - Fish meal & 75,0 & \\
\hline 16,6 & Caséine - Casein & 80,0 & \multirow{6}{*}{ ZEBROWSKA (1973) } \\
\hline 16,5 & Gluten - Wheat gluten & 83 & \\
\hline 17,7 & $\begin{array}{l}\text { Tourteau de soja cru } \\
\text { Raw soya bean meal }\end{array}$ & 67 & \\
\hline 18,2 & $\begin{array}{l}\text { Tourteau de soja cuit } \\
\text { Heated soya bean meal }\end{array}$ & 69 & \\
\hline 16,3 & $\begin{array}{l}\text { Féverole } \\
\text { Horse bean }\end{array}$ & 61 & \\
\hline 10,9 & Orge - Barley & 73 & \\
\hline 13,5 & $\begin{array}{l}\text { Gluten blé + lysine } \\
\text { Wheat gluten + lysine }\end{array}$ & 92,6 & $\begin{array}{l}\text { WUNSCHE et al. } \\
\text { (1979) }\end{array}$ \\
\hline 16,0 & $\begin{array}{l}\text { Poisson (base maïs) } \\
\text { Fish meal (with maize) }\end{array}$ & 84,8 & \multirow{6}{*}{$\begin{array}{l}\text { DARCY, LAPLACE } \\
\text { \& VILLIERS } \\
(1980 \mathrm{~b})\end{array}$} \\
\hline 16,0 & $\begin{array}{l}\text { Poisson (base blé) } \\
\text { Fish meal (with wheat) }\end{array}$ & 83,0 & \\
\hline 16,0 & $\begin{array}{l}\text { Poisson (base maïs) } \\
\text { Fish meal (with maize) }\end{array}$ & 86,5 & \\
\hline 16,0 & $\begin{array}{l}\text { Gluten (base maïs) } \\
\text { Wheat gluten (with maize) }\end{array}$ & 92,1 & \\
\hline 16,0 & $\begin{array}{l}\text { Poisson (base blé) } \\
\text { Fish meal (with wheat) }\end{array}$ & 83,6 & \\
\hline 16,0 & $\begin{array}{l}\text { Gluten (base blé) } \\
\text { Wheat gluten (with wheat) }\end{array}$ & 90,9 & \\
\hline
\end{tabular}


Les digestibilités apparentes obtenues pour nos régimes protéiprives apportant 1,25 p. 100 de protéines brutes sont à rapprocher des valeurs rapportées par ZebrowsKa \& BURACZEWSKa (1972), soit 55 p. 100 pour un régime protéiprive apportant 0,1 p. 100 de protéines brutes ou 62,7 p. 100 pour un régime protéiprive à 3,1 p. 100 de protéines brutes. La valeur la plus basse $(28,7$ p. 100) est rapportée par Holmes et al. (1974) pour un régime apportant 3,2 p. 100 de protéines brutes. Les quantités d'azote endogène recueillies à l'extrémité de l'intestin grêle, exprimées en $\mathrm{mg}$ pour $100 \mathrm{~g}$ de matière sèche ingérée, sont respectivement de 71 et $128 \mathrm{mg}$ dans le cas des régimes protéiprives maïs et blé. Ce mode d'expression permet diverses comparaisons. Ainsi, l'azote endogène représente 90 à $200 \mathrm{mg}$ au niveau fécal selon les éléments réunis par EgGum (1973) et les résultats de PastuszewsKa et al. (1974). On peut aussi noter que la quantité résiduelle d'azote endogène à la fin de l'intestin grêle, chez nos porcs recevant un régime protéiprive, est plus faible que celle qui apparaît au même site chez le veau préruminant $(220 \mathrm{mg}$ - TovLlec, communication personnelle).

Alors que la proportion d'azote soluble dans l'azote total des aliments est extrêmement différente selon la source protéique, il n'existe plus aucune diflérence significative au niveau des digesta quittant l'intestin grêle, quelles que soient la nature de l'amidon et la source protéique. Du fait de cette analogie de la teneur de l'azote total en azote soluble, quel que soit le régime, la différence significative des quantités résiduelles (en p. 100 de l'azote ingéré) d'azote total selon la source protéique est simplement retrouvée de façon également significative sur les quantités résiduelles d'azote soluble. Pourtant, selon Zebrowska (1973), la proportion d'azote soluble dans l'azote total des contenus d'iléon est plus élevée (60 p. 100 environ) pour des régimes gluten et caséine que pour des régimes orge (43 p. 100) et féverole (33 p. 100), pour lesquels la digestibilité de l'azote total est moins bonne. Selon nos résultats, il n'est cependant pas possible d'établir une relation entre la digestibilité de l'azote total et la proportion d'azote soluble qu'il comporte. Dans le cas du poisson, Low (1979) enregistre une digestibilité de l'azote total au niveau de l'iléon de 75 p. 100, pour une proportion d'azote soluble dans cet azote total de 47,5 p. 100 . Les valeurs correspondantes sont dans notre cas de 83,6 à 86,5 (digestibilité) et de 75,3 à 78,5 p. 100 (proportion d'azote soluble). Les quantités d'azote soluble recueillies en 24 heures et exprimées en p. 100 de lazote total ingéré $(11,4$ et 14,8 p. 100 pour les régimes poisson et 5,3 et $6,6 \mathrm{p} .100$ pour les régimes gluten) sont du même ordre que celles enregistrées par Low (1979) : 13 p. 100,6 p. 100 et 12 p. 100 respectivement pour les régimes tourteau d'arachide, caséine et poisson ou par ZeBrowska (1973) : 12,4 p. 100 et 10 p. 100 respectivement pour les régimes caséine et gluten. Les valeurs obtenues par ces auteurs pour une même source protéique telle que la caséine sont largement différentes (12,4 p. 100 contre 6 p. 100), ce qui souligne l'importance probable de l'interférence des autres constituants du régime.

\section{En conclusion}

L'analyse de variance appliquée aux bilans de la digestion montre que : (i) la nature de l'amidon purifié influence significativement la digestibilité apparente de l'azote du régime qui est meilleure avec l'amidon de maïs qu'avec celui de blé ; (ii) la source de protéines alimentaires affecte de façon significative la digestibilité apparente 
de la matière sèche et celle de l'azote qui sont plus élevées avec le gluten de blé qu'avec la farine de poisson; elle influence également de façon significative la digestibilité apparente de l'amidon qui est meilleure avec la farine de poisson qu'avec le gluten de blé ; (iii) il existe une interaction significative entre amidon et protéines à l'égard de la digestibilité apparente de l'azote qui est la plus élevée pour l'association maïs-gluten. Les meilleures digestibilités observées peuvent être reliées à des particularités constatées dans la cinétique de passage : débit maximum plus tardif (matière sèche en régime gluten) ou débit plus régulier au cours du temps (azote en régime gluten ou amidon en régime poisson).

$\mathrm{Au}$ total, pour les régimes concernés, c'est la digestibilité apparente de l'azote qui s'avère, à l'extrémité distale de l'intestin grêle, la plus affectée par la nature de l'amidon et la source de protéines du régime. Cependant l'existence d'une interaction interdit de définir une fois pour toutes l'influence de tel constituant de la ration considéré isolément. Ceci signifie que la digestibilité apparente dans l'intestin grêle doit être évaluée pour chaque association d'un amidon et d'une protéine.

Accepté pour publication en mars 1981.

\section{Summary}

\section{Digestion in the pig small intestine \\ 4. Kinetics of the passage of digesta at the ileo-caeco-colic junction and digestion balances according to the dietary starch and protein}

The respective influences of the kind of starch and of the dietary protein source as well as of their interaction on digestion in the small intestine, were studied. The diets (table 2) were formulated at a $16 \mathrm{p} .100$ crude protein level according to the factorial combination of two kinds of purified starch (maize or wheat) and two dietary protein sources (fish-meal or wheat gluten). In addition, protein free diets based either on maize or on wheat starch were used. The qualitative and quantitative kinetic aspects of the passage of digesta (wet digesta, dry matter, starch, total nitrogen and soluble nitrogen) were considered all together at the distal end of the small intestine. For that purpose, eight Large White castrated male pigs were fistulated according to the recently developed technique i.e. ileo-colic post valve fistulation to allow total collection of digesta just as they leave the small intestine through the ileo-caeco-colic junction.

The main conclusions as regards the overall digestion results at the distal end of the small intestine may be formulated on the basis of the analysis of variance : (i) the kind of dietary purified starch had a significant influence on the apparent nitrogen digestibility, better for maize starch than for wheat starch diets; (ii) the dietary protein source had a significant influence on the apparent digestion coefficients of dry matter and nitrogen, better for diets including wheat gluten as compared to fish meal, as well as on the apparent digestibility of starch, better for fish meal than for wheat gluten diets; (iii) there was a significant interaction between the kind of starch and the protein source as concerns the apparent nitrogen digestibility which was the highest for the diet including maize starch and wheat gluten. The improvement of the digestibility at the end of the small intestine might be related in most cases to some peculiarities of the kinetics of the passage of digesta : the maximum flow rate of dry matter was delayed after a wheat gluten test meal ; the rate of flow of nitrogen (wheat gluten diets) and that of starch (fish meal diets) were more steady along the post prandial hours.

The nitrogen apparent digestibility was the most influenced at the distal end of the small intestine by the kind of starch and protein used. However, the significant interaction between them means that the specific influence of any protein source cannot be stated alone. Therefore, the apparent digestibility in the small intestine must be evaluated for each starchprotein association. 


\section{Remerciements}

Les auteurs tiennent à remercier $\mathbf{M}$. Toullec pour l'intérêt qu'il a porté à ce travail et les conseils dont il les a fait bénéficier.

\section{Références bibliographiques}

Cuber J.C., Laplace J.P., 1979. Evacuation gastrique de l'amidon et de l'azote d'un régime semi-purifié à base d'amidon de maïs chez le Porc. Ann. Zootech., 28, 173-184.

DarCY B., 1980. Contribution à l'étude de la digestion dans l'intestin grêle chez le Porc : Etude de l'interaction entre la nature de l'amidon et la source protéique du régime. Thèse Doct. Ing., Paris, 107 p.

Darcy B., Laplace J.P., 1980. Digestion dans l'intestin grêle chez le Porc. 1) Définition des conditions d'obtention des digesta. Ann. Zootech., 29, 137-145.

Darcy B., Laplace J.P., 1981. Bilans nutritionnels chez le Porc selon la nature de l'amidon (blé ou maïs) et la source de protéines (poisson ou gluten). Ann. Zootech., 30, 63-76.

Darcy B., Laplace J.P., Villiers P.A., 1980 a. Digestion dans l'intestin grêle chez le Porc. 2) Cinétique comparée de passage des digesta selon le mode de fistulation, iléo-caecale ou iléo-colique post-valvulaire dans diverses conditions d'alimentation. Ann. Zootech., 29, $147-177$.

Darcy B., Laplace J.P., Villiers P.A., 1980 b. Digestion dans l'intestin grêle chez le Porc. 3) Cinétique de passage de l'amidon et de l'azote au niveau iléal selon le mode de fistulation, la nature de l'amidon et le taux de protéines de l'aliment. Ann. Zootech., 29, 277-298.

EgGUM B.O., 1973. A study of certain factors influencing protein utilization in rats and pigs. Beretning fra forsogsaboratoriet, $\mathrm{n}^{\circ} 406,173 \mathrm{p}$.

Guilloteau P., Toullec R., 1980. Digestion of milk protein and methanol-grown bacteria protein in the preruminant calf. 1) Kinetics and balance in the terminal small intestine and faecal balance. Reprod. Nutr. Develop., 20, 601-613.

Holmes J.H.G., Bayley H.S., Horney F.D., 1973. Digestion and absorption of dry and high moisture maize diets in the small and large intestine of the pig. Br. J. Nutr., 30, 401-410.

Holmes J.H.G., Bayley H.S., Leadbeater P.A., Horney F.D., 1974. Digestion of protein in small and large intestine of the pig. Br. J. Nutr., 32, 479-489.

Ivan M., Farrell D.J., 1976. Nutritional evaluation of wheat. 5) Disappearance of components in digesta of pigs prepared with two reentrant cannulae. Anim. Prod., 23, 111-119.

KoBILINSKy A., 1980. MODLI - Software for the treatment of the linear model on a minicomputer in Barritt M.M. and Whishard T., Compstat, Proc. in computational statistics, chap. V : Analysis of variance and covariance, 167-173, Physica-Verlag, Wien.

Laplace j.P., Pons O., Cuber J.C., Kabore C., Villiers P.A., 1981. Effets de la nature de l'amidon (blé ou maïs) et des protéines (poisson ou gluten) sur les facteurs de contrôle et le décours de l'évacuation gastrique d'un régime semi-purifié chez le Porc. Applications de l'analyse multidimensionnelle et de la régression polynomiale. $A n n$. Zootech., 30 (sous presse). 
Laplace J.P., Roman C., 1979. Activités de la musculature gastro-intestinale et mouvements des contenus digestifs. Ann. Biol. anim. Bioch. Biophys., 19, 849-879.

Low A.G., 1979. Studies on digestion and absorption in the intestines of growing pigs. 5) Measurements of the flow of nitrogen. Br. J. Nutr., 41, 137-146.

Pastuszewska B., Duee P.H., Henry Y., Bourdon D., Jung J., 1974. Utilisation de la féverole entière et décortiquée par le Porc en croissance : digestibilité et disponibilité des acides aminés. Ann. Zootech., 23, 537-554.

Wünsche J., Bock H.D., Hennig U., Kreienbring F., Borgmann E., 1979. Untersuchungen über die Protein-verdaulichkeit und Aminosaürenresorption in verschiedenen Abschnitten des Verdauungstraktes beim Schwein. 2). Die Protein und Aminosaürenbilanz am Ende des Dünndarms und des gesamten Verdauungstraktes (Scheinbare und wahre Protein und Aminosaürenverdaulichkeit). Arch. Tierernähr., 29, 221-234.

ZebrowsKa T., 1973. Influence of dietary protein source on the rate of digestion in the small intestine of pigs. 1) Amount and composition of digesta. Rocz. Nauk. Roln., 95, 115-133.

Zebrowska T., BuraczewsKa L., 1972. Influence of dietary protein level on the rate of digestion in the small intestine of pigs. 2) The rate of protein digestion and absorption of amino acids (en polonais). Rocz. Nauk. Roln., 94, 97-109.

Zebrowska T., Buraczewska L., Buraczewski S., Horszczaruk F., 1975. Digestion and absorption in the small intestine of pigs. 1) Digestion and absorption of dry matter and nitrogen. Rocz. Nauk. Roln., 96, 79-90. 